University of Louisville

ThinkIR: The University of Louisville's Institutional Repository

Electronic Theses and Dissertations

8-2013

\title{
Characterization of promoter regions of parotid gland genes.
}

Sara M. Perez 1987-

University of Louisville

Follow this and additional works at: https://ir.library.louisville.edu/etd

\section{Recommended Citation}

Perez, Sara M. 1987-, "Characterization of promoter regions of parotid gland genes." (2013). Electronic Theses and Dissertations. Paper 1115.

https://doi.org/10.18297/etd/1115

This Master's Thesis is brought to you for free and open access by ThinkIR: The University of Louisville's Institutional Repository. It has been accepted for inclusion in Electronic Theses and Dissertations by an authorized administrator of ThinkIR: The University of Louisville's Institutional Repository. This title appears here courtesy of the author, who has retained all other copyrights. For more information, please contact thinkir@louisville.edu. 


\title{
CHARACTERIZATION OF PROMOTER REGIONS OF PAROTID GLAND GENES
}

\author{
By \\ Sara M. Perez \\ B.S., University of Georgia, 2010

\begin{abstract}
A Thesis
Submitted to the Faculty of the

University of Louisville School of Dentistry

In Partial Fulfillment of the Requirements
\end{abstract} \\ For the Degree of \\ Master of Oral Biology \\ School of Dentistry \\ University of Louisville \\ Louisville, KY
}

August 2013 



\section{CHARACTERIZATION OF PROMOTER REGIONS OF PAROTID GLAND GENES}

By

Sara M. Perez

B.S., University of Georgia, 2010

A Thesis Approved on

July 9,2013

by the following Thesis Committee:

Douglas S. Darling, PhD, Thesis Director

David Scott, PhD

Brian Shumway, DDS 


\section{ACKNOWLEGDMENTS}

I would like to thank Dr. Douglas S. Darling for allowing me to be part of his lab. He has challenged my mind and supported me the entire time I have been here. The skills and knowledge I have obtained from being a graduate student in his lab will benefit my future endeavors in dentistry. I would also like to thank my committee members Dr. David Scott and Dr. Brian Shumway for being supportive of my research and giving me advice along the way. I would not have been able to do my research without the technical laboratory skills I have learned from Anne Carenbauer. I am appreciative of the guidance and skills I learned from Dr. Venkatesh Srirangapatnam.

I would like to thank my parents and my sister for their constant support and love they have given me during my time as a graduate student. They have encouraged me from the very beginning to the very end. I also would like to thank my wonderful boyfriend Nick Nelson and his family for encouraging me to pursue this masters degree. 


\section{ABSTRACT \\ CHARACTERIZATION OF PROMOTER REGIONS OF PAROTID GLAND GENES}

Sara M. Perez

July 9,2013

BACKGROUND: Salivary secretion aids in digestion, host defense, and lubrication. Parotid salivary gland defects from Sjogren's Syndrome affect more than one million Americans and cause dry mouth leading to oral disease. The Amylase 1 gene and the PSP gene are markers of parotid gland differentiation and indicate normal parotid gland function. Transcriptional activators of genes involved in parotid differentiation have not been characterized.

HYPOTHESIS: Characterizing transcriptional activating sites in gene promoter regions will confirm upstream activating factors in bioinformatic network pathways.

METHODS: Two promoter regions of mouse amylase 1 were identified using the ECR Browser, PCR amplified and ligated into a pGL4.10 luciferase vector. Transcriptional repressor binding sites were identified and removed from the 1 kbp region, followed by PCR amplification to produce fragments that were ligated into the minimal promoter pGL4.23 luciferase vector. These promoter clones were then transfected into three cell lines and tested for promoter activity. 
Bioinformatic analysis of microarray data determined correlations between increased transcription factor expression and markers of parotid differentiation. A hypothetical transcription factor network was created. Two interactions from the network predicted to activate the NUPR1 gene were Cited2/p300 and IRF2/PCAF. Mist1 was suggested to activate the PSP gene based on the hypothetical network. The promoter regions of NUPR1 and PSP were transfected into a parotid acinar cell line, and promoter activity was determined using dual luciferase assays with an internal Renilla control.

RESULTS: The four amylase promoter clones, R1, R2-R1, 900bp, and 700bp were repressed as compared to a promoterless negative control, pGL4.10. The NUPR1 promoter was not activated by the co-transfected combination of Cited2/p300 or IRF2/PCAF. The PSP promoter alone was not activated by Mist1 transcription factor. However, PSP was activated when Mist1 was co-transfected with Tcf3 transcription factor and when intron regions containing E-box binding sites were added to the PSP promoter clone.

CONCLUSION: Amylase 1 was not activated in the regions tested; therefore the active regions of the amylase 1 gene must be outside the $3 \mathrm{kbp}$ region tested. NUPR 1 is not activated by the predicted interactions of Cited2/p300 or IRF2/PCAF, so the results do not support the hypothetical transcription factor network. The PSP proximal promoter is not activated by Mist1, but a PSP promoter + intron construct is activated when the transcription factor Tcf3 + Mist1 are co-transfected. 


\section{TABLE OF CONTENTS}

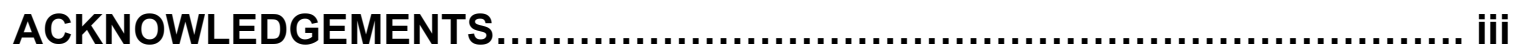

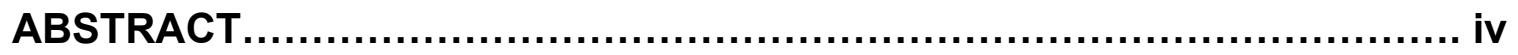

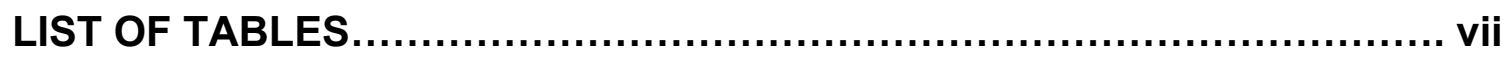

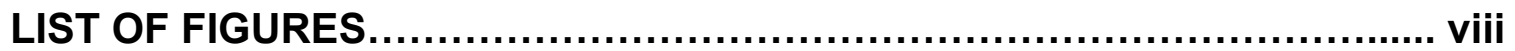

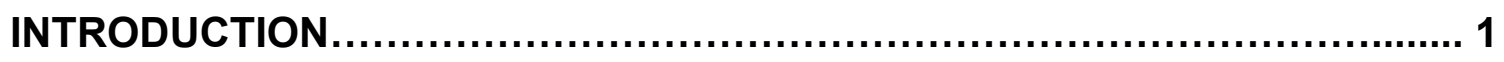

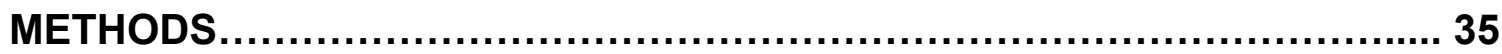

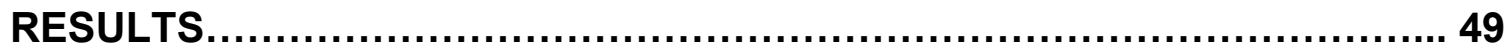

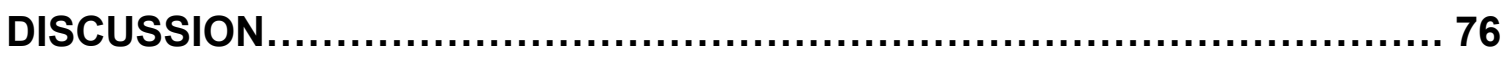

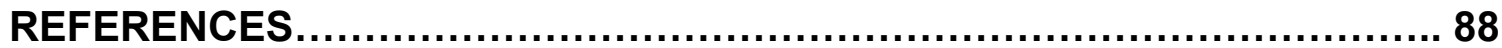

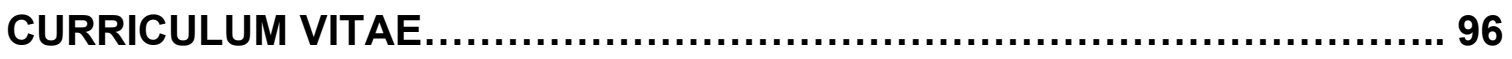




\section{LIST OF TABLES}

Table 1: PCR primers for mouse amylase 1 promoter clones............... 40

Table 2: Mutagenesis primers for Mist1 mutant pGL4.10 and PSP 2kb

promoter clones........................................................................ 43 


\section{LIST OF FIGURES}

Figure 1: Transcription factor expression during parotid differentiation..... 9 Figure 2: Hypothetical transcription factor network regulating parotid differentiation.................................................................... 11

Figure 3: Mouse amylase 1 promoter clones................................. 52

Figure 4: Rat amylase 1 promoter activity in ParC5 cells................... 53

Figure 5: Mouse amylase 1 promoter activity in different cell lines......... 54 Figure 6: Activity of mouse and rat amylase 1 promoter with repressor sites removed in different cell lines................................................... 55

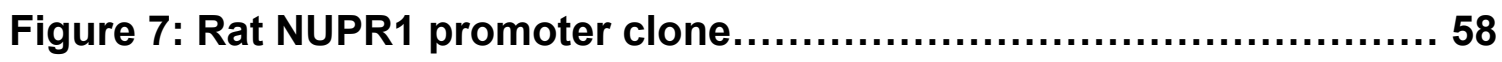

Figure 8: Effect of Cited2 + p300 on NUPR1 promoter activity...............59

Figure 9: Effect of IRF2 + PCAF on NUPR1 promoter activity...............61

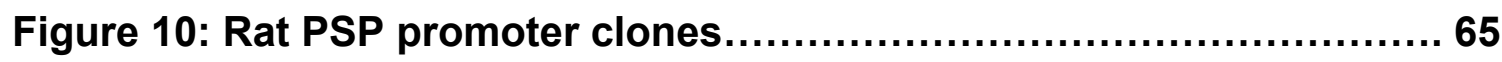

Figure 11: Rat PSP 2kb promoter construct with E-box binding sites for

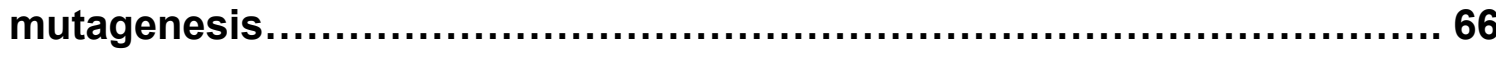

Figure 12: Effect of Mist1 on non-mutant and E-box mutant

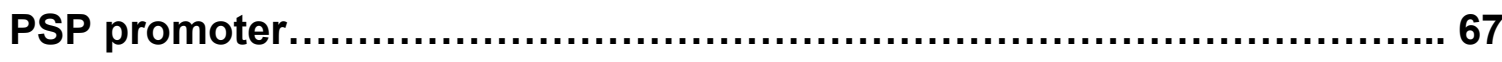

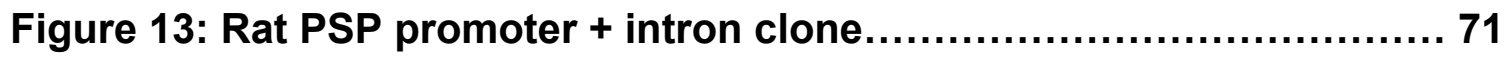

Figure 14: Effect of Mist1/Tcf3 combination on PSP promoter and PSP

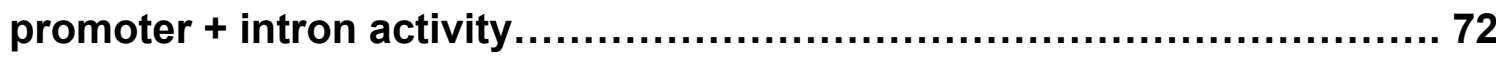


Figure 15: Effect of Tcf3 alone, Mist1 alone, or Mist1/Tcf3 combination on PSP promoter and PSP promoter + intron activity .......................... 74 


\section{INTRODUCTION}

\section{SALIVARY GLAND}

In mammals, there are three major types of salivary glands: the parotid gland, the submandibular gland, and the sublingual glands; and there are minor glands as well [1, 2]. The function of salivary glands is to secrete components that make up saliva. A healthy adult secretes, on average, $500-1500 \mathrm{~mL}$ of saliva per day [2, 3]. Saliva secretion can by stimulated by smell, taste, chewing, psychological and hormonal status, drugs, age, hereditary influences, oral hygiene, and physical activity.

Secretory cells in the salivary glands are specialized epithelial cells, and are classified as serous cells, which secrete a watery fluid, or mucous cells which secrete a mucin-rich fluid [2]. Each salivary gland secretes the components of saliva from a cluster of cells termed acini, the main secretory unit. Acinar cell secretions include water, electrolytes, mucus, enzymes, and other proteins [2]. Alpha-amylase is an enzyme secreted by acinar cells that breaks down starch into glucose. Ductal cells are also contained in salivary glands and are involved in modifying primary saliva and transporting saliva to the oral cavity [4].

Saliva is either secreted in response to a neural stimulus (regulated secretion) or constitutively secreted from the apical membrane of acinar cells [5]. The saliva composition from regulated or constitutive secretion varies [2]. Regulated secretion is distinguished by large, dense secretory granules that 
contain $80-90 \%$ of the total proteins secreted from parotid acinar cells [6]. Constitutively secreted proteins are different from regulated secretion in that they are contained in immature secretory granules that contain lysosomal and other non-salivary proteins.

Water making up saliva crosses epithelial cells in an anion dependent process [1]. Vesicles in the cell bring membrane ion transport proteins to the cell membrane, and these proteins allow the movement of sodium, chloride, and bicarbonate into the acini lumen [7]. The transport of these anions into acini creates an osmotic gradient allowing the transport of water into the lumen. Water helps complete saliva formation. Since water is a required component of saliva, salivary glands require very high fluid transport per unit surface area [8, 9]. Water channels called aquaporins have been found in salivary cells and aid in water transport. Aquaporin-5 is located in the apical membrane of salivary cells. A knockout model of aquaporin- 5 decreased salivary fluid secretion by $50 \%$, indicating its importance in saliva formation [8].

Each type of salivary gland secretes a different type of saliva due to different glandular content of serous cells and mucous cells [2]. The parotid gland is located in subcutaneous tissue of the face overlying the mandibular ramus and secretes serous type saliva containing the most abundant proteins of saliva: amylase, proline-rich proteins, and parotid secretory protein (PSP) [1-3, 5]. The sublingual gland is beneath the tongue and secretes a mucus substance. The submandibular gland is found beneath the lower jaws and secretes a combination of proteins and mucus. Other components present in the mixed 
saliva of the mouth, but not produced by salivary glands, are gingival crevicular fluid, serum transudate from mucosa and inflammatory sites, epithelial and immune cells, and microorganisms [2].

Saliva has a wide array of functions that protect the mouth against infection by microorganisms. Saliva aids in host defense, digestion, and lubrication [10]. Saliva lubricates the hard and soft oral surfaces with a saliva film containing mucins, proline-rich-proteins (PRP's), and water allowing for ease of speech, mastication, and swallowing [11]. Saliva helps neutralize oral cavity $\mathrm{pH}$ after food ingestion and removes food and microorganisms to maintain oral hygiene [2]. Mucins in saliva bind to bacteria and prevent them from adhering to the tooth enamel. Lysozyme in saliva also lyses bacteria and prevents rampant growth of oral bacterial colonies. The binding of mucins and the action of lysozymes, in combination with histatins and other proteins, aid in the antibacterial and antiviral activities of saliva [12].

Salivary glands begin development in the embryo and go through branching morphogenesis [13]. In the rat, parotid gland development begins around the fourteenth day of gestation [14]. From this point the oral epithelium thickens and grows into the mesenchyme as a bud. Epithelial cells proliferate and begin the process of repeated branching and cleft formation. The lumen develops and the gland differentiates into acinar and ductal components until the mature parotid gland is formed $[13,14]$.

Parotid gland development can be divided into four stages. The first stage is the prenatal period beginning at the initiation of gland development until birth. 
This period is characterized by cell proliferation, epithelial branching with terminal clusters and ductal structures, and an absence of secretory granules [14]. The next stage, neonatal period, is characterized by acinar cells differentiating to active secretory cells. The transitional period has the complete adult morphology and secretory proteins found in an adult gland. Acinar cells continue to grow in size, rough endoplasmic reticulum content, and secretory granules. Ducts form their elongated branching structure. The fully mature gland is found in the adult period of parotid development.

Infection, inflammation, head and neck radiation therapy, medications, and Sjögren's Syndrome (SS) can compromise salivary gland function [5, 15]. Sjögren's Syndrome is an autoimmune disease affecting the salivary and lacrimal glands characterized by lymphoplasmocytic infiltration of the tissues [16]. Sjögren's Syndrome can be classified as primary SS or secondary SS, depending on the absence or presence of other connective tissue diseases. About one-third of primary SS patients will develop malignant lymphoma. Characteristic symptoms of Sjögren's Syndrome include decreased tear production by the lacrimal glands and xerostomia, or dry mouth, caused by salivary gland dysfunction [17]. Xerostomia causes issues with mastication, swallowing, and taste $[3,15]$. More importantly, xerostomia can affect oral health causing increased oral disease, such as periodontitis, and dental caries.

Diagnosing SS has been, and continues to be, a challenge. There are two factors that clinicians must deal with when diagnosing a patient with SS: assessing the ocular and salivary components of the disease and distinguishing 
between primary and secondary SS variants [18]. These two factors have led to classification criteria that are not used consistently from clinician to clinician around the world [18]. The American-European Group has revised and established diagnostic criteria for SS [18, 19]. At least four out of six subjective criteria and three out of four objective criteria must be met to diagnose SS. These criteria include subjective and objective ocular dryness, subjective and objective oral dryness, presence of Sjögren-specific antibody A (SSA) or Ro, and/or Sjögren-specific antibody B (SSB) or La [18, 19].

Diagnostic testing for SS includes looking at saliva components (sialochemistry) such as determining the presence of autoantibodies in saliva, and/or looking at salivary flow rates (sialometry) of whole saliva or glandular saliva [2, 20]. Limitations to analyzing saliva composition is that this can only diagnose SS when major changes occur, and sialochemical analysis cannot always be performed because amounts of saliva are insufficient to test [20]. Another test to assess salivary gland function is an invasive biopsy of minor salivary gland tissue. This allows clinicians to evaluate the degree of lymphoplasmocytic infiltration within the harvested glands and is an important objective criterion in the diagnosis of SS [18]. The risks with biopsy are the patient's lip can be left numb after the procedure and false negatives can occur.

Once a patient is diagnosed with SS, the goal is to restore salivary gland function. If there is still viable glandular tissue, cholinergic medications such as pilocarpine and cevimeline will stimulate saliva production [3]. In addition, artificial salivas and other oral hygiene products can help keep the mouth moist 
but some patients still struggle to find relief. Research is currently in progress looking at salivary gland regeneration by expressing growth factors and transcription factors expressed during development. Also, gene therapy using the adenovirus-mediated water channel (aquaporin-1, AQP1) gene has shown increased salivary flow rate in rats $[3,21]$. The AdhAQP1 gene was expressed in a miniature pig model that showed dose-dependent, transient increase in parotid salivary flow $[3,22]$. Baum et. al. have begun a Phase I clinical trial testing AdhAQP1 in human subjects [23]. Through the first 42 days of this trial his group has found the use of an Ad5 vector to be safe, an increase in parotid flow rate, and the peak salivary flow rate is variable and occurs later than animal studies [23]. This clinical trial holds hope for the use of gene therapy for parotid gland dysfunction.

The lack of sufficient treatment for salivary gland dysfunction and initial research for gene therapies support aims focusing to confirm gene expression and transcription factor pathways involved during parotid gland differentiation. These pathways could shed light on new diagnostics or therapeutics to help patients suffering from parotid gland ablation. The research described and data provided in this thesis was aimed at confirming a few of the many regulatory pathways involved in parotid gland differentiation. The following sections will describe genes that are markers of parotid gland terminal differentiation and some of the transcription factors that regulate these genes. 


\section{TRANSCRIPTION FACTORS EXPRESSED DURING PAROTID DIFFERENTIATION}

Molecular mechanisms are involved in parotid gland differentiation. Dr. Venkatesh Srirangapatnam performed analysis of mRNA expression across the process of rat parotid gland development. The heat map created from this analysis observed changes of mRNA expression of transcription factors from embryonic days to postnatal days (Figure 1). From this data, statistical analysis combined similarly expressed groups of transcription factors in a hierarchical clustering. This clustering observed four distinct stages of parotid differentiation. The model suggested by the clustering is that transcription factors increased in the first cluster turn on expression of transcription factors in subsequent clusters eventually leading to activation of expression of gene markers of parotid differentiation, such as amylase I and PSP. My goal has been to contribute to defining the progressive regulatory steps that lead to expression of markers of differentiation of the parotid.

The mRNA analysis, along with Ingenuity Pathway Assist (IPA) analysis, was used to create a hypothetical network of transcription factors involved in parotid differentiation. IPA is a system that analyzes a list of genes and helps model gene interactions using a knowledge base of reported gene function [24]. Gene interactions generated by IPA were depicted in a hypothetical transcription factor network (Figure 2). Some of these interactions were validated in the laboratory, but some still needed to be confirmed. These pathways are the basis of the research presented in this thesis. The goal of this research was to 
characterize promoter regions of parotid gland gene markers by validating the transcription factor networks designated A, B, and C on the hypothetical transcription factor network in Figure 2. The specific goals were to test the promoter regulation of mus Amylase-1 gene, rat NUPR1 gene, and rat PSP gene in a parotid acinar cell line. Analysis of transcription factor expression helped suggest different regulatory pathways in parotid gland differentiation. This mRNA expression analysis aided in selecting the gene promoters and the transcription factor interactions studied. Also, amylase-1 and PSP have been cited in the literature numerous times as markers of differentiated parotid acinar cells, so it was important to identify the active promoter regions and/or activating transcription factors involved in the expression of these genes. The goal of confirming the activation of each promoter is described in the sections below. 
Figure 1: Transcription factor expression during parotid differentiation.

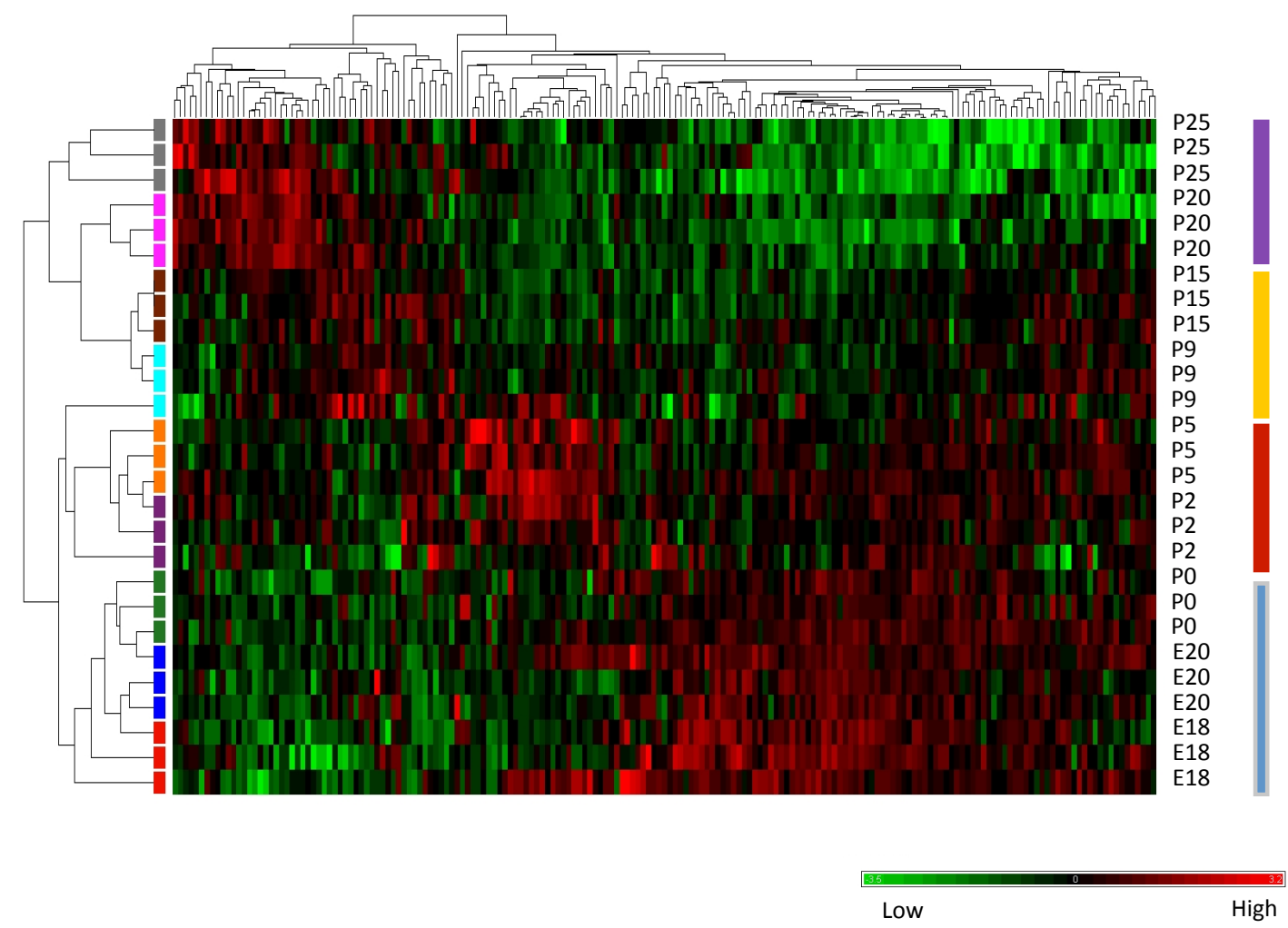

Figure 1: Heat map of transcription factors expressed during parotid

differentiation. Each column represents an individual transcription factor mRNA.

Each row represents an individual rat parotid gland time point starting at embryonic day 18 (E18) and ending at postnatal day 25 (P25), represented on the right side of the heat map. The left side of the heat map is a hierarchical clustering of similarly expressed transcription factors. Parotid differentiation can be clustered in four groups according to this analysis. Transcription factors expressed in low concentrations are represented by green and those expressed in higher concentrations are represented by red. The model is that in some cases transcription factors in the first cluster activate transcription factors in the second 
cluster and continues until the transcription factors eventually turn on markers of differentiation, such as amylase I or parotid secretory protein, (PSP). 
Figure 2: Hypothetical transcription factor network regulating parotid differentiation.

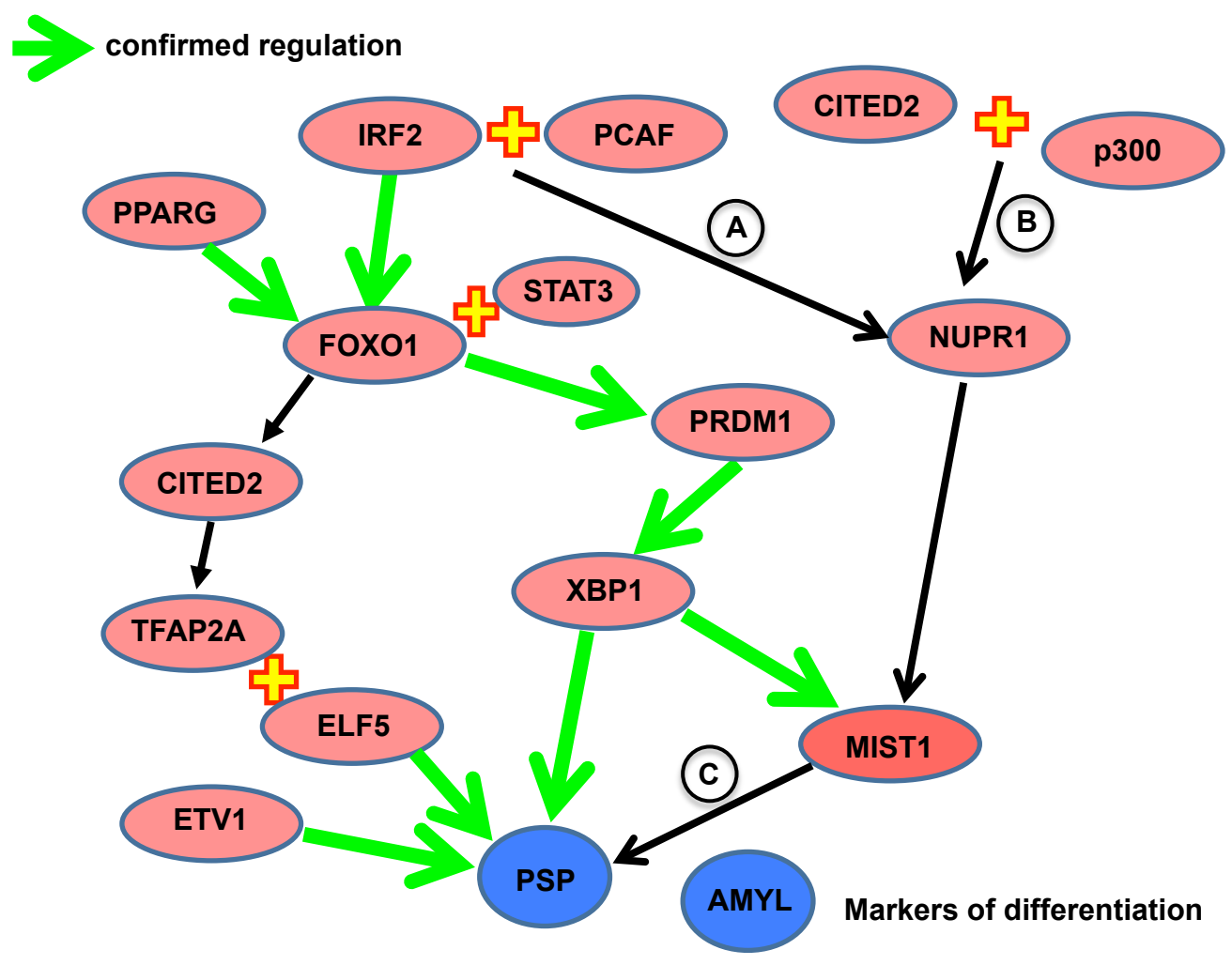

Figure 2: This network shows transcriptional activators regulating parotid differentiation based on Ingenuity Pathway Assist (IPA) analysis. Transcription factor genes expressed differentially in parotid differentiation were of interest and this pathway was created. The green arrows represent confirmed interactions. The black arrows represent interactions that still need to be confirmed. Experiments performed to confirm some of these interactions included testing the interactions labeled A, B, and C. 


\section{AMYLASE I GENE}

Amylase is a marker of terminal differentiation of the parotid gland and is a gene of interest in this research. Amylase has two genes located on mouse chromosome three $[25,26]$. The first locus corresponds to Amy-1, which is strongly expressed in the salivary gland, and the second locus is Amy-2, which is expressed in the pancreas. The Amy-1 gene is expressed as two different mRNA products with one in the parotid gland and the other in the liver. The coding sequence for liver and parotid alpha-amylase is the same with the 3' nontranslated region and part of the 5' non-translated region being identical. The extreme 5 ' leader sequence is unrelated with no sequence homology found between parotid alpha-amylase and liver alpha-amylase. Mouse Amy-2 shares $90 \%$ homology to parotid and liver alpha-amylase, but it has a very short 5' untranslated region and the coding region is shorter [27]. Amy-1 and Amy-2 both have ten exons coding for alpha-amylase. However, Amy-1 has two exons containing 5 ' untranslated leader sequence corresponding to the parotid alphaamylase exon that is separated from the first coding exon by $7.8 \mathrm{~kb}$, and the liver alpha-amylase exon that is $4.9 \mathrm{~kb}$ from the first coding exon. Alpha-amylase mRNA is about 10 -fold less in parotid acinar cells than pancreatic cells [28]. Liver alpha-amylase levels are even lower making up $1 / 100^{\text {th }}$ of parotid levels and $1 / 1000^{\text {th }}$ of pancreatic levels. Pancreatic amylase is expressed in all mammals, but salivary amylase is specific to primates, rodents, and lagomorphs [29].

A chapter written describing murine alpha-amylase describes two Amy-1 promoters with tissue specific expression, the parotid promoter, $\mathrm{P}_{\mathrm{P}}$, and the liver 
promoter, $\mathrm{P}_{\mathrm{L}}$ [28]. Endogenous RNA was isolated from rat liver and parotid cells [26]. Rat liver and parotid mRNA were fractionated on a gel and hybridized to a probe complementary to the first exon of the liver-specific mouse Amy-1 mRNA. Liver-specific amylase transcripts were detected, but parotid-specific transcripts were not detected. Next, rat liver and parotid mRNA was hybridized to a primer complementary to most of the coding region of the parotid mRNA. This probe detected large amounts of parotid-specific alpha-amylase transcripts. These results confirm that amylase is being specifically transcribed in the liver and parotid glands. Primer extensions assays used a radioactive labeled probe that was hybridized to rat parotid mRNA and was extended to determine the location of the transcription start site for parotid Amy-1 in the mouse and rat [26]. Experiments done in vitro helped validate the transcription start sites of the parotid promoter and the liver promoter. Results from these experiments showed that polymerase II molecules involved in transcription initiated at two different start sites. Since the proximal upstream region to the transcription start site is usually assumed to be the promoter, the parotid and liver amylase promoters were predicted to be in these regions.

The parotid promoter was observed to be about 30 -fold stronger than the liver promoter in hepatocytes, giving the terms "strong promoter" to the parotid $\left(P_{p}\right)$ and "weak promoter" to the liver $\left(P_{L}\right)$. The liver promoter was active in liver, parotid, and pancreas with no apparent physiological relevance of the liver transcript in the parotid or pancreas. The transcriptional activity of the parotid promoter increases alpha-amylase levels about 100 -fold in the saliva of weaning 
rats to make up about $97 \%$ of amylase transcripts in adult saliva [30]. The liver promoter is active soon after birth and by two weeks of age the activity of the liver promoter is that which is found in the adult parotid. Transcripts produced from $P_{P}$ are found in all acinar cells at three weeks of age.

The activity of mouse $P_{P}$ and $P_{L}$ was tested by transfecting the $1 \mathrm{kbp}$ proximal promoter region in cell lines that do not have endogenous Amy-1 expression [28]. The chapter mentioned above describing murine alpha-amylase noted (but did not present data) on the activity of $P_{L}$ and $P_{P}$. $P_{L}$ was active in stably transfected mouse L cells, and was transiently expressed and activated in many of the cell lines tested. Importantly, the endogenous $P_{P}$ had been found to be about 30 -fold in vivo more efficient than $\mathrm{P}_{\mathrm{L}}$, but transfected $\mathrm{P}_{\mathrm{P}}$ promoter was not active in any cell lines tested. The conclusion made from these experiments was that $P_{P}$ is more controlled than $P_{L}$, probably due to $P_{L}$ 's lower tissue specificity and to its activity in less differentiated parotid acinar precursor cells. Also, the results suggest that $P_{P}$ might be regulated by a repressive mechanism. An unpublished observation mentioned by Schibler in the murine alpha-amylase chapter was that the progressive deletion of the 5' flanking region of $\mathrm{P}_{\mathrm{P}}$ found that by removing nucleotides upstream of position -300 relieves the transcriptional repression leading to promoter activation [28].

The human salivary amylase promoter was active in human submandibular gland-derived cell line (HSG) [31]. The human $1 \mathrm{kbp}$ amylase promoter was inserted in an adenovirus containing a luciferase reporter gene. Adenoviral infection of the HSG cell type with the human $1 \mathrm{kbp}$ promoter 
construct observed that this promoter is active. The conclusion based on the transfection studies just described is that the human parotid gland and the murine parotid gland may involve different mechanisms that activate the parotid amylase promoter.

Rat and mouse Amy-1 have some similarities and differences in gene structure and in gene and tissue expression [28]. The similarities between the species are they both contain two promoters, $P_{P}$ and $P_{L}$, there is homology of sequences around $P_{P}$ and $P_{L}$, and $P_{P}$ expression is exclusive to parotid acinar cells. The differences between the two species are that $P_{P}$ and $P_{L}$ are farther apart in the rat, there is a different $\mathrm{P}_{\mathrm{L}}$ start site used, the rat splice donor sites are downstream of the mouse site, and the mRNA is about 300 nucleotides longer than the mouse. The $P_{L}$ is specific to the liver and is not detected in rat parotid acinar cells.

Salivary alpha-amylase protein has various functions in the oral cavity ranging from enzymatic activity to interactions with bacterial species as well as making up other components that aid in tooth formation. Salivary amylase is an abundant enzyme produced primarily from serous cells of the parotid. Human saliva contains on average $0.04-0.4 \mathrm{mg} / \mathrm{mL}$ of amylase constituting up to $5 \%$ of the total salivary protein content [32]. The enzymatic activity of salivary alphaamylase protein is to hydrolyze food starch into maltose and glucose [33]. Specifically salivary alpha-amylase hydrolyzes $\alpha-1,4$-glucosidic bonds in starch, glycogen, and other polysaccharides starting in the oral cavity [34]. Amylase 
enzyme has been shown to function as a monomeric or dimeric protein and requires calcium and chloride ions for full enzymatic function [35, 36].

Salivary amylase indirectly and directly affects oral biofilms by providing carbohydrate nutrients to bacteria, promoting bacterial adhesion to the tooth surface, and binding to oral streptococci at secondary oligosaccharide sites [34, $36,37]$. When tooth surfaces are initially exposed to the oral environment, a thin film absent of cells is formed called the acquired enamel pellicle (AEP) [32]. Amylase has been found as a component of the AEP.

Amylase is highly expressed in the adult parotid gland, so it is important to understand how this gene is regulated [30]. Previous studies found the human proximal parotid amylase promoter to be active, however, recent experiments have observed repressed activity when testing the mouse and rat proximal $1 \mathrm{kbp}$ promoter region and a $3 \mathrm{kbp}$ promoter region. The most recent results suggest that there might be an unidentified upstream activating element allowing activation of the amylase I gene. The hypothesis for my work was that transfecting amylase I promoter clones containing different promoter regions in different cell types will activate the promoter region. Mouse and rat amylase I promoter clones were made containing a $1 \mathrm{kbp}$ proximal promoter region, and one clone was made containing both the $1 \mathrm{kbp}$ proximal promoter region and a 2 $\mathrm{kbp}$ region about $2.5 \mathrm{kbp}$ upstream of the proximal promoter region of both the mouse and rat amylase 1 gene. Sequence analysis of the mouse $1 \mathrm{kbp}$ promoter region identified transcriptional repressor binding sites. A $900 \mathrm{bp}$ and a $700 \mathrm{bp}$ promoter clone were made with these sites removed. The promoter fragments 
were ligated into a luciferase reporter vector. The promoter clones were tested for promoter activity by transient transfection studies, and were transfected in three different cell types. The rat amylase promoter clones were transfected in a parotid acinar cell type. Amylase promoter activity was measured by performing assays that measured firefly luciferase expression, and transfection efficiency was measured by performing assays measuring renilla luciferase expression. The promoter activity was determined by normalizing firefly luciferase RLU values to renilla luciferase RLU values.

\section{NUPR1 GENE}

NUPR1, nuclear protein 1, or p8, was first discovered as a gene activated in the acute phase of pancreatitis [38]. It has been shown to have increased levels in developing pancreas and liver [39]. Screening of human pancreatic cDNA library characterized the NUPR1 gene as having three exons and two introns with 5' and 3' untranslated regions, and the gene is located on chromosome 16 [40]. The NUPR1 protein has a bipartite signal for nuclear localization suggesting it functions in the nucleus. It also contains a basic helixturn-helix motif that allows the protein to bind DNA as a transcription factor [38-

40]. Mallo et. al. performed northern blot analysis to analyze NUPR1 mRNA [39]. They found NUPR1 was highly expressed in salivary glands and expressed to a lesser extent in stomach, colon, liver, and kidneys. The brain, spleen, testes, thymus, and skeletal muscles all had an absence of NUPR1 mRNA. Tissues expressing NUPR1 only express this gene in exocrine cells [39]. The NUPR1 
gene has been further characterized by parotid gland mRNA analysis as well as data showing high NUPR1 expression in salivary glands, localization of expression in acinar cells.

NUPR1 gene expression has not been characterized in parotid gland differentiation. NUPR1 mRNA had elevated expression in the analysis of transcription factors involved in parotid gland differentiation. Transcription factors that increased in expression at the same time as NUPR1 were tested as possible activators of NUPR1 gene expression. These transcription factors included Cited2 and IRF-2. A detailed explanation of these transcription factors and the co-factors p300 and PCAF are described in following sections. The hypothesis for this section of the research was that NUPR1 promoter activity would increase when a Cited2/p300 combination or an IRF-2/PCAF combination is cotransfected. The cDNA combinations and the NUPR1 promoter driving luciferase were transiently expressed in ParC10 and 3T3-L1 cells to determine promoter activity.

\section{PAROTID SECRETORY PROTEIN}

Parotid secretory protein (PSP) was first identified as a leucine-rich protein in rat saliva samples, and was later found as a major protein component of mouse saliva [41]. PSP is found located on mouse chromosome two and on rat chromosome three. Murine PSP is first detected in embryonic terminal clusters and lumina, and the levels continue to increase throughout development, reaching high levels in the adult gland [14]. PSP is an abundant product of 
mouse parotid acinar cells, and is found in low levels in sublingual serous cells [4]. The mRNA levels of PSP in parotid acinar cells is about $10 \%$ of the total cellular mRNA and about ten fold lower in sublingual glands [4, 42]. Poulsen et. al. performed northern blot analysis of mouse tissue and quantified PSP mRNA expression in various tissues [30]. They found the mouse parotid gland had the most abundant PSP mRNA, with lesser amounts found in submandibular and sublingual glands, even lower amounts in the pancreas, and undetectable amounts in the liver. Another finding from this experiment was that the tissue specific expression of mouse PSP parallels levels of mouse amylase expression. The conclusion from this data is that PSP and amylase are expressed in the mouse parotid gland. In humans, PSP mRNA expression is found in the submandibular and parotid glands [43].

PSP belongs to the PLUNC (palate, lung, and nasal epithelium clone) protein family, which consists of mucosal secretory proteins [44]. Specifically, rodent PSP is the orthologue of the human PLUNC protein, SPLUNC2 [45]. PLUNC proteins are related to the BPI/LBP/CTEP lipid-binding protein family. Bactericidal/permeability-increasing protein (BPI) and lipopolysaccharide binding protein (LBP) bind lipopolysaccharide (LPS) constituents of bacterial cells walls on Gram-negative bacteria, lipoteichoic acids of Gram-positive bacteria, and lipoarabinomannas of mycobacteria [46]. LPS receptors of macrophages and neutrophils recognize LPS bound to BPI or LBP and result in a cellular response that destroys the invading pathogen or renders the pathogen inactive [43]. Since PSP, PLUNC, and BPI/LBP proteins are related, it has been suggested that PSP 
may function similarly to the BPI/LBP proteins. These predicted functions include binding to bacteria and having an antibacterial effect, having growth-suppression effects on bacteria, promoting anti-inflammatory effects, and causing bacterial agglutination [45]. Gorr et. al. expressed PSP in the rat cell line GH4C1 to test PSP antibacterial activity [47]. Their data resulted in reduced colony numbers of Pseudomonas aeruginosa supporting evidence for PSP bactericidal activity, and they also observed reduced E. coli colony numbers presumably due to PSP enhancing bacterial agglutination. This data support the idea of PSP being antibacterial and helping agglutinate bacteria.

Nothing is known about the characterization of the PSP gene. A significant goal of this work is to determine transcription factors that enhance PSP promoter activity. Mist1 was a transcription factor predicted in the hypothetical network to activate the PSP gene. The hypothesis was that Mist1 transcription factor or a Mist1/Tcf3 transcription factor combination will activate the PSP promoter. The goals of PSP promoter experiments were to determine if Mist1 activates the PSP promoter, and to determine if mutating Mist1 DNA binding sites, or E-box sequences (described in the following sections), will prevent PSP promoter activation. Another goal of testing PSP gene activation was to test the affect of Mist1 on other locations of the PSP gene. One group found that Mist1 activated the Mindbomb 1 gene (Mib1) through the first intron [48]. E-box binding sites were found in the second and third introns of the PSP gene. This region was ligated into a PSP promoter-luciferase clone, and transient transfection studies were performed to test Mist1's affect on the PSP promoter + intron clone. The 
next goal was to co-transfect the E-protein, Tcf3, with Mist1 to see the combinatorial effect of the transcription factors on the PSP promoter and PSP promoter + intron

\section{CITED2 AND P300 TRANSCRIPTIONAL CO-ACTIVATORS}

In the hypothetical transcription factor network, Cited2 was predicted to activate NUPR1 gene expression. Cited2 belongs to a family of genes known as CITED (CAMP response element binding protein (CBP)/p300 interacting transactivators with ED-rich termini) $[49,50]$. These proteins do not bind DNA, but serve as transcriptional co-activators. Cellular Cited2 binds tightly to the $\mathrm{CBP} / \mathrm{p} 300$ transcription complex, and in turn the $\mathrm{CBP} / \mathrm{p} 300$ complex binds to DNA bound transcription factors to facilitate RNA polymerase II gene transcription [51]. Interaction of Cited2 protein with CBP/p300 regulates pathways influenced by this transcription complex such as co-activation of the transcription factor AP2 [49]. Cited2 protein is involved in organogenesis, and the early stages of adrenal tissue growth and adrenal differentiation [50, 52]. Also, studies performed by Bamforth et. al. used Cited2 null mouse embryos to determine how the absence of Cited2 caused complications in cardiac, neural crest, and neural tube development [53]. They used in vitro binding assays and found the C-terminal end of Cited2 interacts with the transcription factor Tfap2, a factor involved in neural crest and neural tube development. To confirm Cited2 enhances target gene transcription by Tfap2, transient transfection studies found that the activity of a luciferase reporter vector containing Tfap2 binding elements 
increased when Tfap2 and Cited2 were co-expressed, as compared to expression of Tfap2 alone. These experiments confirmed that Cited2 is required for proper development of the neural crest.

The nuclear phosphoproteins, p300 and cAMP response element binding protein (CBP), are homologous and widely expressed [54, 55]. p300 is a coactivator that links DNA-bound transcriptional activators to the basal transcription machinery. It has histone acetyltransferase (HAT) activity that is involved in modifying chromatin structure within gene promoters, and the HAT activity also allows p300 to increase DNA binding efficiency of p300-interacting transcription factors $[56,57]$. Both of these histone modifying actions result in more efficient transcription of target genes. One example of p300 enhancing transcriptional activity of skeletal muscle specific genes is by acetylating the transactivation domain of myocyte enhancer factor 2 (MEF2) to increase its DNA binding ability [56]. Also, nuclear hormone receptors like the thyroid hormone receptor have enhanced transcriptional activity in the presence of $p 300$ [58]. The bHLH skeletal muscle transcription factor, MyoD, requires p300 to fully activate gene promoter targets [57, 59-61]. These examples of p300 helping activate transcriptional activation support the co-expression of p300 with Cited2 in the experiments performed in the research described in this thesis.

Cited2 was of interest in the following research because its mRNA levels increased about the same time as NUPR1 mRNA levels during parotid development. The co-activator, p300, was of interest because it has been cited numerous times in the literature as having interactions with Cited2 to enhance 
gene activation. The hypothesis was that a combination of Cited2/p300 would increase NUPR1 promoter activity. Transient transfection experiments in ParC10 and 3T3-L1 cell types were performed to test the effect of the Cited2/p300 combination on NUPR1 activity.

\section{IRF2 TRANSCRIPTION FACTOR AND PCAF CO-FACTOR}

IRF2 belongs to the interferon regulatory (IRF) transcription factor family. This transcription factor shares sequence homology to the IRF-1 gene in the 5' half of the protein coding region [62]. IRF2 is a nuclear factor that binds various DNA elements. One of these elements in called IRF-E and the consensus sequence is $G(A) A A A G / C T / C G A A A G / C T / C$ [63]. Another sequence IRF-2 binds is the interferon consensus sequence (ICS), also know as the interferon stimulated response element (ISRE), and the DNA binding sequence for this element is A/GNGAAANNGAAACT [64, 65]. One last element IRF-2 binds is known as the positive regulatory domain I (PRDI) of the IFN- $\beta$ gene [66].

IRF-2 is a very stable protein with an eight-hour half-life [67]. The Cterminal domain of IRF-2 is rich in basic amino acids and contains a repression domain [65]. The DNA binding activity is found in the N-terminal domain and consists of three $\alpha$-helices, four-stranded antiparallel $\beta$-sheets, and three long loops [62]. This structure is similar to the binding domain of bHLH proteins (described in a later section), however, the DNA interaction between these two protein families differ [68]. The third $\alpha$-helix of IRF-2 binds the major groove containing the GAAA portion of the IRF-E or ICS binding sites while the other 
binding domain segments interact with the surrounding sequence.

Phosphorylation by protein kinase $A(P K A)$, protein kinase $C(P K C)$, and casein kinase II (CK2) at multiple serine sites affect IRF-2 regulation during cell growth [69].

IRF-2 can act as a transcriptional repressor or a transcriptional activator. Proteolytic cleavage of IRF-2 is induced by interferons, viral infection, or dsRNA treatment and becomes a transcriptional activator or repressor [65]. Once IRF2 is efficiently expressed it represses interferon-stimulated response elements in other genes induced by the interferon stimulus, such as IRF-1 [70]. Hamada et. al. performed transfection experiments comparing the effects of IRF-1 and IRF-2 on IFN- $\beta$ promoter expression in cell culture [62]. This promoter was activated by IRF-1 alone, repressed by IRF-2 alone, and when there was co-expression of IRF-1 and IRF-2 the promoter was repressed. The conclusion from this experiment was that IRF-2 silences IRF-1. Genes that are activated by IRF-2 are the vascular cell adhesion molecule-1 (VACM-1) gene, and the human $\mathrm{H} 4$ histone gene [71, 72]. Jesse et. al. observed the activation of the VCAM-1 gene by IRF-2 in the IRF-E sequence of the gene promoter. Their data indicated that the basic repression domain in the $\mathrm{COOH}$-terminal end was inactive in myoblasts, and that an acidic latent activation domain resides in the central region of the protein. IRF-2 is also involved in cell cycle growth control and cell cycle progression as a transcriptional activator of the human $\mathrm{H} 4$ histone gene, FO108 [69]. 
The transcriptional cofactor p300/CBP-associated factor (PCAF) is mainly located in the nucleus and has histone acetyltransferase (HAT) activity [73-75]. The acetylation occurs post-translationally on the $\mathrm{N}_{\varepsilon}$-amino-group of a lysine residue [76]. These modifications influence protein functions such as proteinprotein interactions, protein association with DNA, and protein stability. PCAF is a subunit of the SAGA-type multi-protein complex that functions as a co-activator of transcription. Transcription is stimulated by the acetyltransferase activity of the complex leading to modification of nucleosomes through interaction with nucleosome remodeling enzymes.

PCAF has numerous targets that regulate different pathways in the body. A few proteins that PCAF targets are tumor suppressors, and modification of these proteins decreases cell growth [73]. The tumor suppressor p53 is acetylated and activated upon DNA damage by PCAF to slow down cell growth and promote apoptosis [77]. Other proteins involved in tumor suppression are p73, which functions similarly to $\mathrm{p} 53$, and Bax proteins that mediate apoptosis $[74,78]$. Contrary to these tumor suppressor targets, PCAF also activates tumor activator protein c-Myc by increasing its stability, which could be one cause of its characteristic overexpression in cancer [79]. Acetylation of the tumor suppressor protein PTEN decreases its potential to inhibit cell cycle progression [80]. An instance where PCAF is required as an activator in non-cancer associated context is by enhancing the activity of the estrogen receptor, the glucocorticoid receptor, and the androgen receptor when the appropriate ligand for these receptors is present [81]. PCAF has been shown to be required for progestin 
induction of target genes [75]. Also, PCAF acetylates and activates the retinoblastoma protein to promote differentiation and to keep this protein localized to the nucleus [82].

IRF-2 has been shown to recruit PCAF in order to enhance its own binding to the ISRE [83]. DNA affinity binding assays and immunoblot assay performed by Masumi et. al. found that IRF-2 directly binds PCAF in order to bind the ISRE. Assays testing the enzymatic activity of PCAF on the ISRE-IRF-2 complex found PCAF is a major contributor to acetylation in this complex. This group also found that PCAF binds the internal DNA-binding domain of IRF-2 using C-terminal truncations of IRF-2. The C-terminal domain of PCAF contains the histone acetylase catalytic domain and a bromodomain, and in vitro experiments support that the bromodomain of PCAF is where IRF-2 binds. IRF-2 has been shown to activate the $\mathrm{H} 4$ gene, so Masumi et. al. ligated the H4 ISRE binding site to a luciferase reporter vector to test promoter activation from IRF-2 and PCAF. The combination of IRF-2 and PCAF yielded higher luciferase activity than IRF-2 alone indicating that PCAF is a co-activator for IRF-2.

In this thesis, the IRF-2 transcription factor was studied to determine its effect on the NUPR1 promoter. The mRNA analysis of transcription factors involved in parotid gland differentiation showed that IRF-2 is at elevated levels as NUPR1 levels increase. This IRF-2 mRNA analysis and the study showing that IRF-2 and PCAF interact and enhance promoter activation led to the decision to co-express this transcription factor and co-activator with the NUPR1 promoter. The hypothesis was that a combination of IRF-2/PCAF would increase NUPR1 
promoter activity. This was accomplished by performing transient transfection experiments co-expressing NUPR1 promoter driving luciferase, and the IRF2/PCAF combination in 3T3-L1 cells.

\section{MIST1 TRANSCRIPTION FACTOR}

Mist1 belongs to the basic helix-loop-helix (bHLH) transcription factor family, specifically class II bHLH proteins $[84,85]$. The bHLH protein family is large and has been organized into different classes (I-VII), each class referring to their tissue expression, DNA-binding abilities, and dimerization properties. These proteins are widely expressed in tissues, form homodimers or heterodimers with other bHLH family members, and bind exclusively to E-box consensus sites [85, 86]. The bHLH-motif contains two amphipathic $\alpha$-helices separated by a variable loop region with a basic region that binds DNA [84]. Dimerization of bHLH transcription factors allows the basic domains to interact and bind the E-box DNA sequence, -CANNTG-, to promote activation of most genes [86-88]. Dimers of bHLH proteins will line up with the E-box DNA sequence so one monomer interacts with one half-site, CAN, and the other monomer interacts with the NTG half-site [85]. Evidence has determined bHLH transcription factors can be "tissuespecific" or "ubiquitous", and family members will have differential expression during development.

Mist1 shares the same bHLH-motif as other bHLH family members, but has a unique $\mathrm{C}$ - and $\mathrm{N}$-terminal domain [84]. The $\mathrm{N}$-terminal domain (repressor domain) has been shown to negatively regulate bHLH-mediated transcription 
[89]. Translocation to the nucleus and formation of homodimers and

heterodimers with E-proteins allows Mist1 to bind E-box consensus DNA binding sites and activate or repress gene expression depending on cellular contexts [84, 90].

Mist1 expression has been found in different species such as mouse, rat, human, and zebrafish [90]. Pin et. al. used a "knock-out" mouse model by replacing a coding region of the Mist1 locus with the bacterial LacZ gene to follow Mist1 mRNA expression and to identify cells that accumulate Mist1 protein [91]. This model was used to create a Mist1-LacZ mouse line. Tissues from these mice were stained for $\beta$-galactosidase (LacZ) to measure levels of Mist1 mRNA expression is different tissues. LacZ expression indicated Mist1 positive tissues. Assays testing Mist1-LacZ mice measured about a 1000-fold increase in LacZ expression in pancreatic and salivary gland tissues compared to Mist1 negative kidney tissue. Mist1 is present in pancreas, parotid gland, submandibular gland, small intestine, male reproductive tract, and stomach secretory cells (mucussecreting cells, parietal cells, and chief cells) because LacZ was also expressed. Mist1 specific polyclonal antibodies were used to examine protein expression in cells. Mist1 was found located specifically in exocrine cells throughout the body with high levels found in pancreatic acinar cells and in salivary glands; specifically in serous cells of the parotid gland and seromucous type cells in the submandibular gland. Cells in the sublingual gland, ductal cells, and endocrine cells were negative for Mist1. Based on work by other groups, other tissues 
found to express Mist1 are chief cells in the stomach, mammary glands, seminal vesicles, and lacrimal glands [90, 92].

Mist1 knockout studies have suggested Mist1 as a regulator of acinar cell polarity and secretory granule formation. Calcium signaling complexes were observed in acinar cells of Mist1 null mice [93]. Calcium signaling is polarized from the apical-to-basal end of exocrine secretory cells and the localization of the calcium signaling complexes and intracellular organelles are important for proper calcium signaling. Digestive enzyme secretion in the pancreas is activated by calcium, and disruption of the calcium signaling of this process has been shown in acute pancreatitis. Mist1 is required for the normal development of serous acinar cells in the pancreas and salivary glands. Mist1 knockout acinar cells have altered calcium signaling due to the mislocalization and aberrant calcium uptake by the mitochondria, which is a key player in controlling the calcium wave from the apical-to-basal end of the cell. The digestive enzyme content in Mist1 null cells is about 2.5 to 3 -fold less in amylase, trypsin, and lipase as compared to wildtype cells, which may be due to a diffuse and fragmented Golgi apparatus. Changing calcium levels in a functioning cell are a major stimulator of exocytosis in pancreatic acini. Stimulated amylase secretion was measured to quantify exocytosis and found that exocytosis was impaired in the Mist1 knockout acinar cells. This result suggested that the lack of exocytosis is due to secretory granules are being mislocated and the calcium signaling complexes were impaired. The study findings just described suggest Mist1 is involved in controlling the localization and integrity of mitochondria and the Golgi apparatus 
and it controls the localization of secretory granules. The findings further support the importance of Mist1 in correct acinar cell formation with properly localized intracellular organelles involved in the apical-to-basal calcium oscillations and waves important to cell function.

Another use of the Mist1 null mice model was studying the effect Mist1 has on Ras-like small GTPases, such as RAB3D and RAB26, that regulate vesicular formation and transport [94]. A chief cell type was studied, the zymogenic cell lineage $(Z C)$, which is a cell located in the base of the gastric unit. Mist1 expression has been shown to begin in easrly stages of ZC differentiation and is involved in the formation and maintenance of secretory granules and apical-basal reorganization. Mist1 null ZC's were observed to have smaller zymogen-containing vesicles and defects in the apical-to-basal organization. Granules are usually found predominately in the apical end of the cell, but the granules in Mist1 null cells were equally distributed in the apical and basal ends. Inappropriate granule trafficking resulted at the basal end, and the nucleus was localized at the apical end. The proteins RAB3D and RAB26 are involved in large granule formation in the gastric epithelial cells. Mist1 was shown to directly bind these RAB proteins in vitro by ChIP analysis on a cell line stably expression Mist1-eGFP. In situ hybridization found RAB3D and RAB26 expression is confined to Mist1 expressing ZCs in wildtpye mice, and laser-capture microdissection (LCM) determined that Mist1 null ZCs had barely detectable levels of RAB26 as compared to background levels, and the RAB3D expression was significantly decreased. These in vivo experiments confirmed that Mist1 
transcriptionally regulates these RABs. These experiments further suggest Mist1 is important to proper secretory granule formation and for proper organelle localization.

The majority of information on parotid secretory protein (PSP) focuses on the protein functions in saliva, but there is not as much information on gene expression of PSP gene. The PSP proximal promoter region has not been characterized. Previous analysis of rat parotid mRNA showed patterns of transcription factors involved in parotid gland differentiation. Mist1 was a transcription factor that had elevated levels as PSP was being expressed. Also, Mist1 DNA binding sites, or E-box sites, were found upon analysis of the PSP promoter sequence. This led to my hypothesis that Mist1 would activate the PSP promoter. The specific aims focusing on proving this hypothesis were to determine if Mist1 activates the PSP proximal promoter, and to determine if mutating E-box sites would prevent Mist1 activation. Transient transfection studies co-expressing rat Mist1 cDNA with rat PSP promoter DNA were used to accomplish these goals.

\section{E2A (Tcf3) TRANSCRIPTION FACTOR}

E2A belongs to the class I bHLH and the E-protein family [86]. The E2A gene, also referred to as Tcf3, encodes two class I bHLH transcription factors, E12 and E47, and the isoforms have been shown to form a heterodimer with Mist1 transcription factor [84-86, 95]. The bHLH-motif of E12 and E47 have conserved residues sharing sequence homology with the Drosophila proteins 
Daughterless, MyoD, and the Myc transcription factor family [85]. The HLH motif provides a dimerization domain of two amphipathic $\alpha$-helices separated by a flexible loop [85]. The E47 dimer forms a four-helix bundle which allows the basic region of the bHLH-motif to contact the major groove of DNA as loop residues and one of the helices contacts DNA surrounding that region [96]. E2A binds Ebox consensus sequences, and this site promotes cell-specific gene expression by regulating promoter and enhancer regions for specific gene expression in muscle, pancreatic, and neuronal cells [85]. This transcription factor is widely expressed in tissues and can act as a transcriptional activator or repressor depending on its binding partner and other co-activators or co-repressors [86].

There are many functions of E2A transcription factor. E2A is essential for B-cell development and activates genes involved in this process [ $85,88,95]$. The two proteins encoded by the E2A gene, E12 and E47, are essential for the progression of early B cells past the very early progenitor stage [95]. The murine mb-1 promoter was studied to understand the control for tissue and differentiation stage-specific transcription in B cell development. E2A isoforms have been shown to bind E-box sequences in this promoter and are required for its activation. Genes specific to pancreatic development contain E-box sequences and require the heterodimer formation of E2A and the class II bHLH BETA2 for pancreatic differentiation [85]. One E2A function that has been suggested is its role in tumor suppression [97]. Mice that were deficient in E2A rapidly developed T-cell lymphomas and loss of E2A homodimers appeared to have a role in T-cell leukemia development. The ectopic expression of E2A in 
mice lacking this transcription factor induced apoptosis and therefore supports its role in tumor suppression. Another way E2A enhances gene activation is by interacting with cofactors such as p300, CBP, and PCAF in the AD1 and AD2 activation domains in the $\mathrm{N}$-terminal $[88,98]$. Both the $\mathrm{E} 12$ and $\mathrm{E} 47$ proteins have been shown to recruit p300, a co-activator with histone acetyltransferase activity involved in chromatin remodeling, and this interaction enhances transcriptional activity [98].

There are also instances of repression by E2A isoforms. The E12/E47 heterodimer have been shown to repress activity on cell-cell adhesion protein Ecadherin during epithelial-mesenchymal-transition (EMT) of embryonic tissue development and of metastases $[86,88,99]$. Also, binding with the class $\mathrm{V}$ bHLH protein, Id, negatively regulates E-protein transcriptional activity. Id proteins lack the basic domain that would bind DNA in target promoters, and this blocks the transcriptional activity of the bound E-protein [100].

Mist1 transcription factor alone repressed PSP promoter activity. Tcf3 transcription factor was utilized as a binding partner for Mist1 in experiments testing the activity of PSP promoter and PSP promoter + intron activity. The hypothesis was that co-transfection of Mist1 and Tcf3 would increase PSP promoter and/or PSP promoter + intron activity. The goals were to determine how the PSP promoter and the PSP promoter + intron clones were affected by the Mist1/Tcf3 combination, and to determine the specific effects of Mist1, Tcf3, and the Mist1/Tcf3 combination. This was accomplished by transfecting ParC10 cells 
and transiently expressing rat Mist1 and rat Tcf3 cDNA with rat PSP promoter or rat PSP promoter + intron regulating luciferase. 


\section{METHODS}

\section{AMYLASE-1 PROMOTER CLONES}

Different amylase 1 (Amy1a) promoter clones were made using the PCR amplification method. The promoter regions were determined using the ECR Browser: Evolutionary Conservation of Genomes website, http://ecrbrowser.dcode.org/. The rat and mouse Amy1a promoter regions were compared on ECR. Conserved regions containing suggested activating transcription factor binding sites were chosen. A 1000 base pair region (mAmyl 1 kb) spanning the proximal promoter, and an adjacent 2000 base pair region (mAmyl R2) were mapped (Figure 1). These regions were cloned into an empty pGL4.10 luciferase vector supplied by Promega. This vector produces luciferase protein that can be used as a measure of promoter activity. Primers flanking the mouse promoter regions of interest were designed for PCR amplification and are listed in Table 1. The forward primer for the 1000 base pair promoter region, termed 'M.Amy1 1kb Bglll For', contains a Bglll restriction site, and the reverse

primer for this region, 'M.Amy1 1kb HindIII Rev', contains a Hindlll restriction site. The forward primer for the 2000 base pair promoter region, 'M.Amy1 Xhol R2 For', contains a Xhol restriction site, and the reverse primer for this region, 'M.Amy1 Bglll Rev', contains a Bglll restriction site. PCR amplification of mAmyl $1 \mathrm{~kb}$ and mAmyl R2 started with an initial denaturation of mouse genomic DNA at $95^{\circ} \mathrm{C}$ for $6: 00$. This was followed by eight cycles of denaturation at $95^{\circ} \mathrm{C}$ for 
thirty seconds, annealing at $58{ }^{\circ} \mathrm{C}$ for thirty seconds, and extension at $72{ }^{\circ} \mathrm{C}$ for two minutes. These eight cycles were followed by twenty-five cycles of denaturing at $95^{\circ} \mathrm{C}$ for thirty seconds, then annealing at $60^{\circ} \mathrm{C}$ for thirty seconds, and extension at $72{ }^{\circ} \mathrm{C}$ for two minutes and ten seconds. The PCR products were purified by spinning down PCR reactions onto a silica membrane using the QIAquick PCR Purification Kit (Qiagen) according to the spin protocol. After being purified, mAmyl 1kb PCR product and an empty pGL4.10 luciferase vector were double digested with BgIII and HindIII restriction enzymes creating fragment ends that hybridized together during a ligation reaction. The mAmyl R2 PCR product and an empty pGL4.10 luciferase vector were double digested with BgIII and Xhol restriction enzymes. The digested promoter fragments and pGL4.10 vectors were purified via gel extraction according to the QIAquick Gel Extraction Kit spin protocol. After quantitating the DNA obtained from the gel extraction, mAmyl $1 \mathrm{~kb}$ was ligated into pGL4.10 digested with Bglll and HindIII, and mAmyl R2 was ligated into pGL4.10 digested with BgIll and Xhol using T4 DNA ligase supplied by Invitrogen. The samples were put in a PCR Thermocycler overnight at $16{ }^{\circ} \mathrm{C}$. The ligation reactions were transformed into TOPO $10 \mathrm{DH} 5-\alpha$ competent cells. Colonies were screened for promoter inserts using the Promega Wizard Plus SV Minipreps DNA Purification System by lysing the cells, removing endonucleases and other proteins released during lysis using an alkaline protease, neutralizing the lysate, and then applying the neutralized lysate to a spin column membrane. Once miniprep DNA was quantified, these clones were screened by restriction enzyme digests. A double digest using enzymes BgIll and 
HindIII were used to determine miniprep samples containing mAmyl $1 \mathrm{~kb}$ inserts. The enzyme Bsal was used to screen for the promoter fragment in the mAmyl R2 miniprep samples. Samples containing correct fragment lengths on a $1 \%$ agarose gel were confirmed by sequencing.

These single promoter fragment clones were then combined to include both promoter fragments in order to test if promoter expression was stronger with the regions together. The promoter fragment, mAmyl R2, was ligated into the mAmyl-1kb-pGL4.10 clone. First, the R2 region was amplified using the same PCR primers listed in Table 1 for the R2 region and the same PCR conditions listed above. After the PCR product was purified, the R2 fragment and mAmyl1kb-pGL4.10 DNA was double digested with Xhol and Bglll restriction enzymes. The mAmyl R2 fragment and mAmyl-1kb-pGL4.10 DNA was purified via gel extraction and then ligated together with T4 DNA ligase. The mAmyl-R1R2.pGL4.10 ligation product was transformed into TOPO 10 DH5- $\alpha$ competent cells. Colonies were chosen and screened for the correct promoter insert using the Promega Wizard Plus SV Minipreps DNA Purification System. The miniprep samples were digested with Sacl enzyme to screen for a clone with the inserted mAmyl R2 region. Samples containing the correctly digested band lengths were confirmed by DNA sequencing.

The 1000 base pair amylase promoter sequence was analyzed for transcriptional repressor binding sites. Promoter clones with these sites removed were cloned into a Promega pGL4.23 luciferase vector. This vector contains a minimal promoter to enhance the DNA region of interest expression. The two 
promoter regions were 900 base pairs and 700 base pairs in length and designated mAmy1-900bp and mAmy1-700 bp. The forward primer used for both was the same primer used for amplifying the 1000 base pair promoter region. The reverse primer used for mAmy1-900bp promoter region was mAmy1 900bp HindIII Rev that contains a HindIII restriction site. The reverse primer for mAmy1700bp promoter region was mAmy1 700bp HindIII Rev also containing a HindIII restriction site. These three primers are listed in Table 1. The PCR conditions used to amplify the promoter regions consisted of an initial denaturation at $95{ }^{\circ} \mathrm{C}$ for six minutes followed by eight cycles of denaturation at $95{ }^{\circ} \mathrm{C}$ for thirty seconds, annealing at $55^{\circ} \mathrm{C}$ for thirty seconds, and extension at $72{ }^{\circ} \mathrm{C}$ for two minutes. These cycles were followed by twenty-five additional cycles of denaturation at $95{ }^{\circ} \mathrm{C}$ for thirty seconds, annealing at $58{ }^{\circ} \mathrm{C}$ for thirty seconds, and extension at $72{ }^{\circ} \mathrm{C}$ for two minutes. The PCR products were purified via the QIAquick PCR Purification Kit following included instructions. Both the 900 base pair and 700 base pair PCR products and a pGL4.23 luciferase vector were digested with BgIII and HindIII restriction enzymes. The digested promoter fragments and the digested pGL4.23 luciferase were gel purified using the QIAquick Gel Extraction kit. After purification, an overnight ligation reaction using T4 DNA ligase was performed at $16{ }^{\circ} \mathrm{C}$ in order to ligate the 900 base pair and 700 base pair promoter fragments into the pGL4.23 vector. The ligation products were transformed into TOPO $10 \mathrm{DH} 5-\alpha$ competent cells. Colonies were grown up and screened for promoter inserts using the Promega Wizard Plus SV Minipreps DNA Purification System. After the DNA was quantified, mAmy1-900bp promoter 
inserts were screened by a BssSI restriction digest, and mAmy1-700bp promoter inserts were screened by a double digest using Notl and Bglll restriction enzymes. The digested DNA was analyzed via gel electrophoresis, and samples with correct band lengths were sent to sequence at the University of Louisville DNA sequencing core. Correct promoter sequences were confirmed and these DNA samples were purified using the QIAfilter Plasmid Midi Prep kit. This DNA purification is a modified alkaline lysis procedure where the neutralized lysate is bound to a QIAGEN Anion-Exchange Resin. After the lysate is applied to the resin, impurities such as RNA are removed by a medium-salt wash, and then an elution with a high-salt buffer concentrates plasmid DNA. The DNA is desalted by isopropanol precipitation.

The NUPR1 promoter region was amplified by PCR and ligated into the pGL4.10 luciferase vector by standard cloning methods as described above. Figure 5 depicts this promoter construct. 
Table 1: PCR primers for mouse Amylase 1 promoter clones

\begin{tabular}{|l|l|l|}
\hline Clone & PCR primer used & Tm \\
\hline & Forward: & For: \\
& 5'-CACCAGATCTCTCAGCTTCAGCATCACATCTCTG-3' & $63.5^{\circ} \mathrm{C}$ \\
& Rev: & Rev: \\
R1 & 5'-CACCAAGCTTCATGTGCTGCCTTCCACTGC-3' & $66.3^{\circ} \mathrm{C}$ \\
\hline & Forward: & For: \\
& 5'-CACCCTCGAGACTCCCTTGCTCCTTGACTCTCAT-3' & $66.8^{\circ} \mathrm{C}$ \\
& Reverse: & Rev: \\
R2 & 5'-CACCAGATCTCATCAGTCCCTTCGTCCATTGTCA-3' & $64.5^{\circ} \mathrm{C}$ \\
\hline & Forward: & For: \\
& 5'-CACCAGATCTCTCAGCTTCAGCATCACATCTCTG-3' & $63.5^{\circ} \mathrm{C}$ \\
& Reverse: & Rev: \\
700bp & 5'-CACCAAGCTTTCTTGGGGGAAAAGGAGTTT-3' & $62.6^{\circ} \mathrm{C}$ \\
\hline & Forward: & For: \\
& 5'-CACCAGATCTCTCAGCTTCAGCATCACATCTCTG-3' & $63.5^{\circ} \mathrm{C}$ \\
& Reverse: & Rev: \\
900bp & 5'-CACCAAGCTTCTTGCATGGATATTTCACTGGT-3' & $62.0^{\circ} \mathrm{C}$ \\
\hline
\end{tabular}




\section{E-BOX MUTANT PSP PROMOTER CLONES}

The PSP 2000 base-pair promoter sequence and the pGL4.10 luciferase vector sequence were analyzed for Mist1 transcription factor binding sites, or an E-box consensus sequence binding site, 5'-CANNTG-3' [85]. Two sites were found in the PSP $2 \mathrm{~kb}$ promoter region, and three sites were found in the pGL4.10 vector. Mist1 transcription factor was predicted to enhance expression of PSP. Ebox sites were mutated in a previously made clone containing the PSP $2 \mathrm{~kb}$ promoter region ligated into pGL4.10.

First, to eliminate any background activity from Mist1 the sites in the pGL4.10 vector were mutated. The sites mutated in pGL4.10 were designated site $A$, site $B$, and site $C$ and are depicted in Figure 11. The mutagenic primers used are listed in Table 2 below. The QuikChange II Site-Directed Mutagenesis Kit supplied by Agilent Technologies was used to perform mutagenesis of the Mist1 sites according to kit instructions. First site A was mutated, and then this confirmed clone was used as a template to mutate site B resulting in a clone that had both sites A and B mutated. Then this double Mist1 mutant clone was used

as a template for mutating Mist1 site C. The final product was pGL4.10 with Mist1 binding sites A, B, and C mutated termed, 'Mist1mut-ABCpGL4.10'. The PCR conditions used for all mutations were an initial denaturation of $95^{\circ} \mathrm{C}$ for thirty seconds, followed by sixteen cycles of denaturation at $95{ }^{\circ} \mathrm{C}$ for thirty seconds, annealing at a temperature specific for the mutagenic primer used for one minute, and extension at $68^{\circ} \mathrm{C}$ for five minutes. After the PCR reaction, PCR products were digested with Dpnl enzyme. Dpnl enzyme digested parental DNA 
that was not mutated during the PCR reaction. The digested product was transformed into TOPO $10 \mathrm{DH} 5 \mathrm{a}-\mathrm{T} 1$ competent cells and plated on ampicillin agar plates. Colonies were chosen, inoculated in LB broth, and grown in order to screen them for correct mutations. The Promega Wizard Plus SV Minipreps DNA Purification System was used to extract DNA from the bacterial cells, the DNA was quantified, and then sent for sequencing. Confirmed sequences with correctly mutated binding sites were purified using the QIAfilter Plasmid Midi Prep Kit via kit instructions.

The next step was to ligate the PSP $2 \mathrm{~kb}$ promoter region into the mutated pGL4.10 vector. The PSP $2 \mathrm{~kb}$ promoter clone previously made in the laboratory, -1980PSPprom.pGL4.10, and the mutated pGL4.10 was digested with Kpnl and Xhol restriction enzymes. The digested fragment and vector were gel purified using the QIAquick Gel Extraction kit. The purified PSP 2kb promoter was ligated into the purified, mutated pGL4.10 using T4 DNA ligase at $16{ }^{\circ} \mathrm{C}$ overnight. The ligation product was transformed into TOPO $10 \mathrm{DH} 5-\alpha$ competent cells. Colonies were inoculated and screened for the promoter insert using the Promega Wizard Plus SV Minipreps DNA Purification System followed by Xhol digest to screen for the correct insert. Samples containing correctly digested band lengths were sent to sequence. The correct sequence was confirmed and the plasmid clone purified using the QIAfilter Plasmid Midi Prep Kit. 
Table 2: Mutagenesis primers for Mist1 mutant pGL4.10 and rat PSP 2kb promoter clones.

\begin{tabular}{|l|l|l|}
\hline Clone & PCR primer used & Tm \\
\hline & Forward: & For: \\
& 5'-CCGCCGGCGAGCAACTTCACAAAGCCATGAAGCGCTAC-3' & $71.0^{\circ} \mathrm{C}$ \\
Mist1 & Reverse: & Rev: \\
site A & 5'-ATGGCTTTGTGAAGTTGCTCGCCGGCGGTCCCGTCTTCGA-3' & $72.8^{\circ} \mathrm{C}$ \\
\hline & Forward: & For: \\
& 5'-GTCCCAGTGCAAGTGGTACTTCCAGAACATTTCTC-3' & $65.0^{\circ} \mathrm{C}$ \\
Mist1 & Reverse: & Rev: \\
site B & 5'-GAGAAATGTTCTGGAAGTACCACTTGCACTGGGGAC-3' & $65.0^{\circ} \mathrm{C}$ \\
\hline & Forward: & For: \\
& 5'-CATGCAACTCGTAGGACTCGAGCCGGCAGCGCTCTTC-3' & $70.5^{\circ} \mathrm{C}$ \\
Mist1 & Reverse: & Rev: \\
site C & 5'-GAAGAGCGCTGCCGGCTCGAGTCCTACGAGTTGCATG-3' & $70.5^{\circ} \mathrm{C}$ \\
\hline & Forward: & For: \\
& 5'-GTGAATGAAGGCACAGCATGCATAGTGTACATGTTG-3' & $63.3^{\circ} \mathrm{C}$ \\
Mist11 & Reverse: & Rev: \\
site 3 & 5'-GTGCCTTCATTCACACATGAGCAACACAC-3' & $61.9^{\circ} \mathrm{C}$ \\
\hline & Forward: & For: \\
& 5'-GCCATTCGGCATTCCTGCGCTTTGAATTGTTTG-3' & $65.0^{\circ} \mathrm{C}$ \\
Mist1 & Reverse: & Rev: \\
site 4 & 5'-CAAACAATTCAAAGCGCAGGAATGCCGAATGGC-3' & $65.0^{\circ} \mathrm{C}$ \\
\hline
\end{tabular}




\section{PSP PROMOTER + INTRON CLONES}

The PSP $2 \mathrm{~kb}$ promoter clone and the E-box mutant PSP $2 \mathrm{~kb}$ promoter clones were repressed by Mist1 transcription factor. Therefore, additional sites in the PSP gene by which Mist1 could activate transcription were sought. There is evidence that Mist1 binds E-box sequences within the first intron of genes, such as the ubiquitin ligase Mindbomb1, Mib1, gene [48]. The intron regions of the PSP gene were analyzed for Mist1 E-box binding sites, and sites were found within the second, third, and fifth introns. PCR primers were made for the regions between the second and fourth exons and between the second and sixth exons, but the region between the second and fourth exons was the only region successfully amplified. This region will be referred to as the PSP intron region. The PCR primers used to clone the intron region were: the forward primer with a Sall restriction site, PSPex2Sall For B: 5' -CAA CTT GTC GAC CTT GTG GTC TTG TGT GGC-3'; the reverse primer with a Sall restriction site, PSPex4Sall Rev: 5'-CAT TGG TCG ACA GCC CAG CTT GAA GAT CC-3'. The PCR conditions used to amplify the PSP intron region consisted of an initial denaturation at $95^{\circ} \mathrm{C}$ for six minutes, followed by eight cycles of denaturation at $95^{\circ} \mathrm{C}$ for thirty seconds, annealing at $61^{\circ} \mathrm{C}$ for thirty seconds, and extension at $72{ }^{\circ} \mathrm{C}$ for two minutes and twenty seconds. After these eight cycles, the reaction underwent twenty-five more cycles of denaturation at $95^{\circ} \mathrm{C}$ for thirty seconds, annealing at $63^{\circ} \mathrm{C}$ for thirty seconds, and extension at $72{ }^{\circ} \mathrm{C}$ for two minutes and thirty seconds. Then the amplified intron region was PCR purified using the QIAquick PCR Purification Kit following the kit instructions. 
The next step was to insert the amplified intron region into the PSP $1.5 \mathrm{~kb}$ promoter construct made previously in the laboratory. The PSP $1.5 \mathrm{~kb}$ promoter was digested with Xhol restriction enzyme and the PSP intron region was digested with Sall restriction enzyme. The Xhol digested promoter was purified via ethanol precipitation and then digested with calf intestinal phosphatase (CIP) enzyme in order to remove phosphate groups to prevent the Xhol cut vector from re-ligating to itself in the ligation step. After CIP digestion, the PSP $1.5 \mathrm{~kb}$ promoter was PCR purified. While the PSP $1.5 \mathrm{~kb}$ promoter was undergoing the various digestions, the PSP intron region was gel purified using the QIAquick Gel Extraction Kit. The purified PSP $1.5 \mathrm{~kb}$ promoter and the purified PSP intron region were ligated together and incubated overnight at $16{ }^{\circ} \mathrm{C}$. The ligation reaction was transformed into TOPO $10 \mathrm{DH} 5-\alpha$ competent cells and plated on LB plates containing ampicillin. Colonies were inoculated the next day and prepped for screening the PSP intron region using the Promega Wizard Plus SV Minipreps DNA Purification System. Miniprep samples were digested with Nhel enzyme to screen for the PSP intron insert in the PSP $1.5 \mathrm{~kb}$ promoter. Samples with correctly digested band lengths were sent to the DNAcore for sequencing. After the correct sequence was confirmed, the PSP promoter + intron sample was purified using the QIAfilter Midi Prep Kit.

\section{TRANSFECTIONS}

Transfections allow testing of exogenous, functional DNA by introducing the DNA of interest into a mammalian cell type. A cationic lipid reagent is added 
to a reaction containing the DNA of interest. The positive charge of the cationic lipid interacts with the negatively charged DNA backbone, and the positive charge of the lipids allows the DNA-lipid complex to cross the negatively charged, hydrophobic cell membrane [101]. The promoter activity of the amylase1, NUPR1, PSP promoter (non-mutant and mutant), and PSP promoter + intron clones were tested by transfecting each DNA into mammalian cell lines. Each promoter had been cloned adjacent to the luciferase coding sequence, such that activation of the promoter stimulates luciferase enzyme expression, which is easily measured.

Amylase-1 was transfected into ParC5, 3T3-L1, and JEG-3 cell lines. ParC5 cell type is an immortalized rat parotid acinar cell line, 3T3-L1 cell type is a mouse embryonic fibroblast cell line, and JEG-3 cell type is a human choriocarcinoma cell line [102-104]. The NUPR1 promoter was tested in ParC10 and 3T3-L1 cell types. ParC10 cell line is a slightly different immortalized rat parotid acinar cell line than ParC5. The transfection reagent used for amylase-1 promoter and NUPR1 promoter experiments was lipofectamine. The optimized amylase-1 promoter transfection conditions for ParC5 cells, 3T3-L1 cells, and JEG-3 cells were as follows: cells were split into a six-well plate at 100,000 cells per well; the total DNA used for experiments testing amylase-1 promoter activity was $1500 \mathrm{ng}$; the DNA:lipofectamine ratio for was 2:3. The optimized NUPR1 promoter transfection conditions for ParC10 cells were 250,000 cells per well in a six-well plate, $640 \mathrm{ng}$ of total DNA was transfected, and the DNA:lipofectamine ratio was 1:8. The optimized conditions for 3T3-L1 cells were 100,000 cells per 
well were plated in a six-well plate, $800 \mathrm{ng}$ of total DNA was transfected, and the DNA:lipofectamine ratio was 1:4. Renilla luciferase was transfected at the same concentration in the amylase-1 promoter and NUPR1 promoter experiments and used as a measure of transfection efficiency.

The PSP 2kb promoter (non-mutants and E-box mutants) and PSP promoter + intron DNA clones were tested in ParC10 cells, another immortalized rat parotid acinar cell line [105]. The transfection reagent used for experiments testing PSP 2kb promoter (non-mutant and E-box mutant) was FugeneHD. The optimized transfection conditions for these experiments were cells were plated at 60,000 cells per well in a 24 -well plate, the total DNA concentration transfected was $200 \mathrm{ng}$, and the DNA:FugeneHD ratio used was 1:8. Renilla was used as the measure of transfection efficiency in experiments testing E-box mutant PSP 2 $\mathrm{kb}$ promoter activity until the renilla activity was repressed. Cypridina luciferase was tested as the measure of transfection efficiency, and Mist1 did not repress the values measuring Cypridina. Cypridina was then used in the remaining E-box mutant PSP $2 \mathrm{~kb}$ promoter experiments and in all experiments testing PSP promoter + intron activity.

\section{FIREFLY LUCIFERASE, RENILLA LUCIFERASE, AND CYPRIDINA LUCIFERASE ASSAYS}

All the promoter constructs used in the transient transfection assays were ligated into a vector containing the luciferase gene. The amount of luciferase protein synthesized is a measure of promoter expression [106]. After the 
transfected cells were allowed to grow for 48 hours, the media was removed and passive lysis buffer was applied to each well. The lysates from each well were tested for promoter activity by performing luciferase assays. The firefly luciferase substrate was injected into each individual sample and the relative light units (RLU) were measured by a luminometer. Renilla luciferase substrate and cypridina luciferase substrates were injected into another set of the same samples to test transfection efficiency. The final promoter activity was measured as the ratio of firefly luciferase RLU values:renilla luciferase or cypridina luciferase RLU values. 


\section{RESULTS}

\section{CHARACTERIZING THE PROXIMAL PROMOTER OF THE AMYLASE I GENE}

Alpha-amylase (Amy-1) is an important and abundant protein in saliva that helps digest starch to maltose and glucose [33]. The Amy-1 gene is highly expressed in fully differentiated parotid acinar cells [30]. Schibler et. al. determined and showed activation of the amylase 1 promoter region years ago [28]. Since then there has been little investigation into characterizing the Amy-1 promoter region even though the protein is a major component in saliva. Recent experiments performed in the laboratory have found this region to be inactive, contradicting Schibler's results. The goal of studying the Amy-1 promoter was to determine active regions upstream of the transcription start site. Determining the active promoter will allow future work to define transcriptional activator sites

within this region. Previously, a colleague in the laboratory performed transfections in ParC5 cells testing the activity of the rat amylase I R2-R1 promoter construct. The results from luciferase and renilla assays show this promoter region is less active than the negative control, pGL4.10; therefore, the promoter is inactive (Figure 4). Since the amylase I gene between the rat and mouse is conserved, mouse amylase I clones were made to test promoter expression.

The amylase I promoter clones used in this work are listed in Table 1 and Figure 3. A 1,000 bp promoter region (R1) directly upstream of the transcription 
start site was ligated into a pGL4.10 luciferase. The levels of promoter activity are determined by measuring luciferase expression. A 2,000 bp promoter region (R2) directly upstream of the 1,000 bp region was ligated into the R1 amylase I promoter clone.

To test amylase I promoter activity, the mouse R1 and mouse R2-R1 clones were transfected in ParC5, 3T3-L1, and JEG-3 cell lines. The harvested cell lysates were measured for promoter activity by luciferase assays and the transfection efficiency was measured by renilla luciferase assays. Promoter activity was determined by normalizing average luciferase values to average renilla luciferase values. As shown in Figure 5, mouse amylase I R1 promoter and mouse amylase R2-R1 promoter activity is less than the negative and positive controls. These results were demonstrated in three different cell lines confirming the amylase promoter regions tested were repressed. After seeing the repressed promoter activity, sequence analysis was done and identified multiple transcriptional repressor sites in the $\mathrm{R} 1$ region.

Amylase promoter clones with the repressor sites removed were made for both the mouse and rat. A 900 bp promoter clone eliminated GFI1, ZEB1, and FREAC4 transcription factor binding sites. A 700 bp promoter clone eliminated GFI1, ZEB1, FREAC4, and two CHOP transcription factor binding sites (Figure 3). Both promoter clones with these sites removed were ligated into the minimal promoter pGL4.23 luciferase vector. The sequences of each promoter clone were confirmed. The purified amylase I promoter clones were transfected in ParC5, 3T3-L1, and JEG-3 cell lines to test promoter activity. Data obtained from 
luciferase and renilla assays show amylase promoter activity is still repressed compared to the promoterless negative control, pGL4.23, in each cell line tested (Figure 6). These data indicate that the regulatory region of amylase I gene are outside the 3,000 bp region tested. Initial work with the parotid amylase promoter looked at its endogenous expression and found the promoter to be inactive. Even though an unpublished observation found a $300 \mathrm{bp}$ amylase promoter to be active, this small promoter region would not benefit the goal of identifying active sites. The data agree with the literature that the mouse amylase promoter constructs tested were not active in different cell types. 
Figure 3: Amylase I Promoter Clones

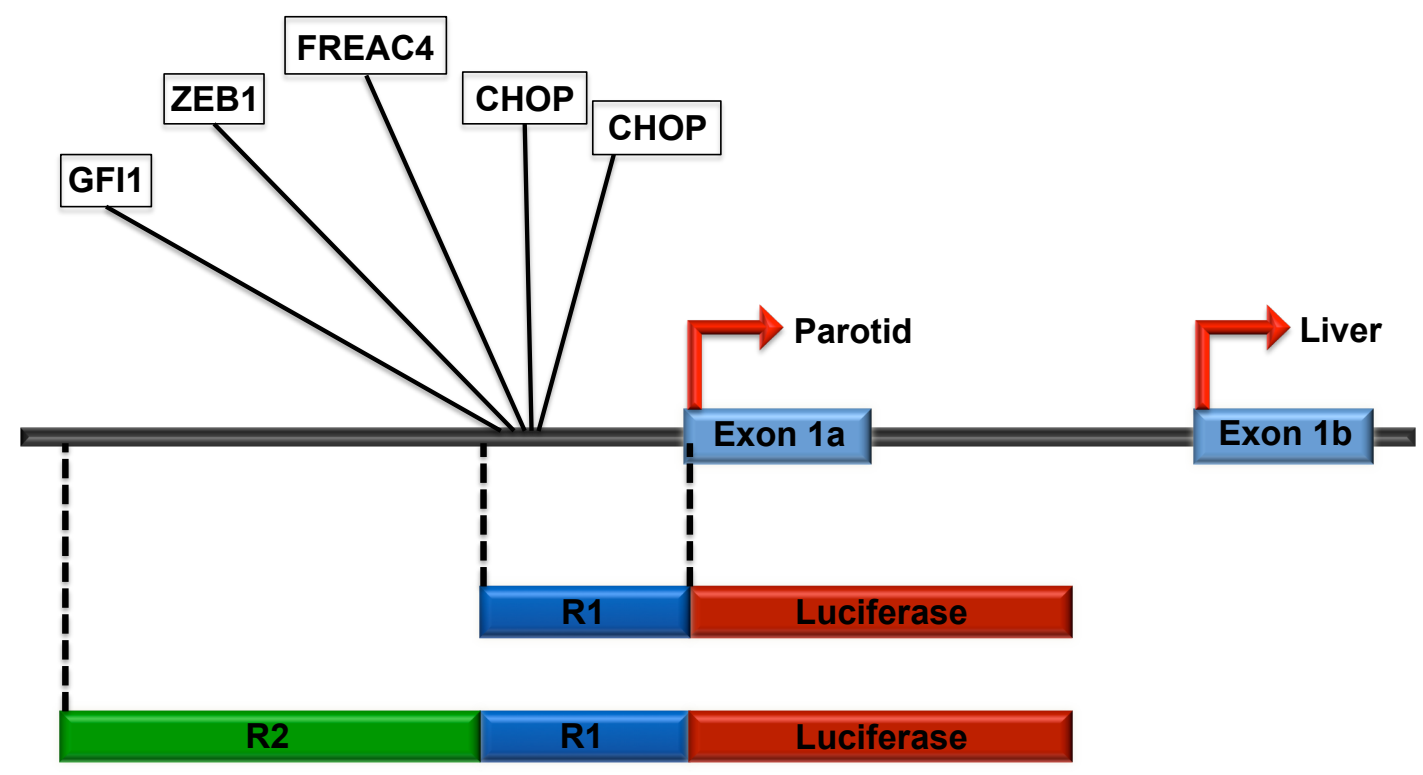

Figure 3: A diagram of the amylase I promoter regions used in transfection experiments. The transcription start sites for the parotid and liver are shown. The constructs for the $1 \mathrm{~kb}$ promoter, represented here as $\mathrm{R} 1$, and the $2 \mathrm{~kb}$ promoter region added to the $1 \mathrm{~kb}$ promoter clone, represented here as $\mathrm{R} 2$, are shown ligated to the pGL4.10 luciferase vector. The transcriptional repressor binding sites are indicated in the $\mathrm{R} 1$ promoter region. 
Figure 4: Rat Amylase promoter activity in ParC5 cells

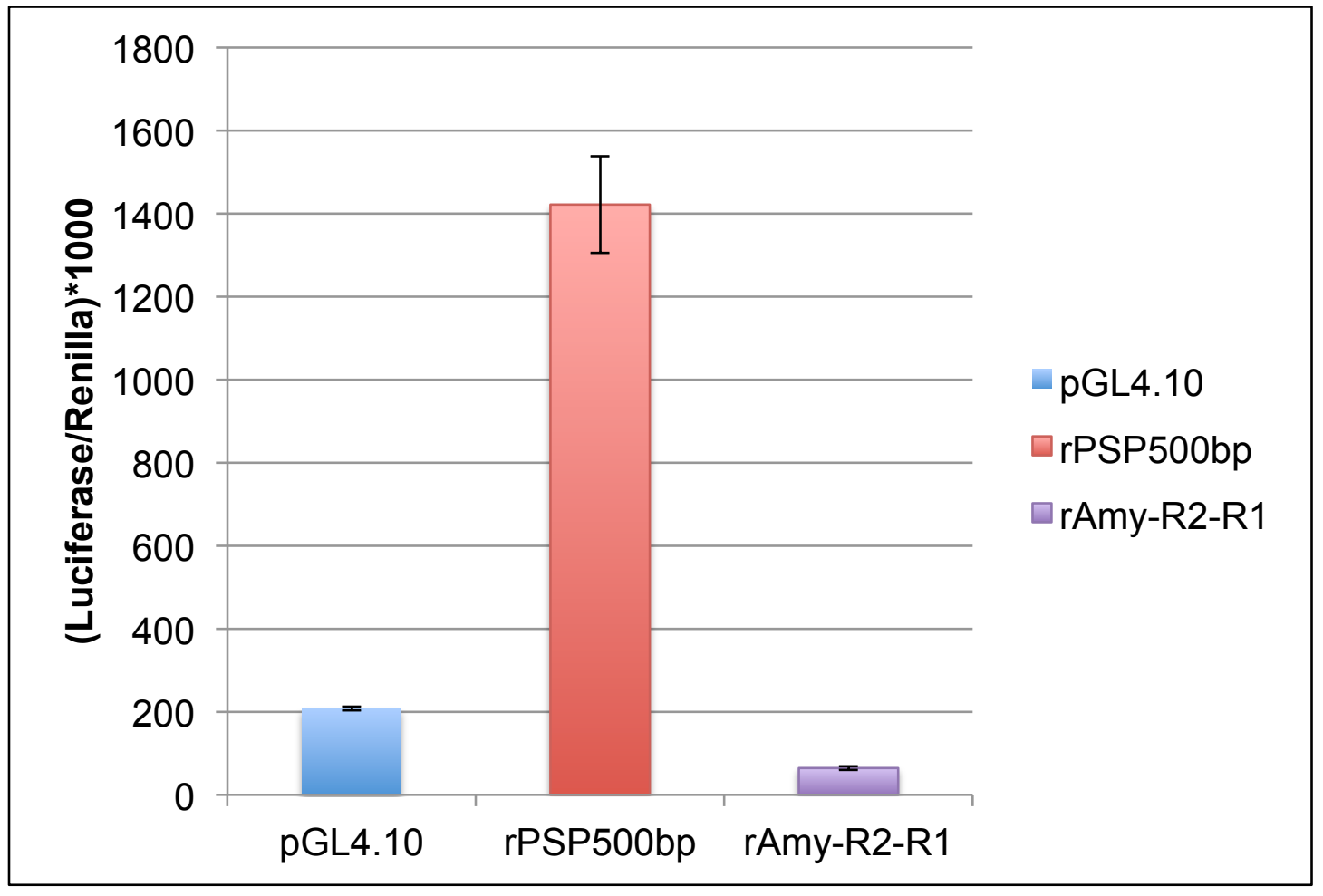

Figure 4: Testing the activity of rat amylase R2-R1 promoter. The activity of rat amylase I promoter is compared to a negative control, pGL4.10, and a positive control rat PSP 500 bp promoter. The rat amylase promoter has lower activity compared to the negative and positive controls. $\mathrm{N}=1$ independent experiment done with triplicate wells. 
Figure 5: Mouse amylase I promoter activity in different cell lines.

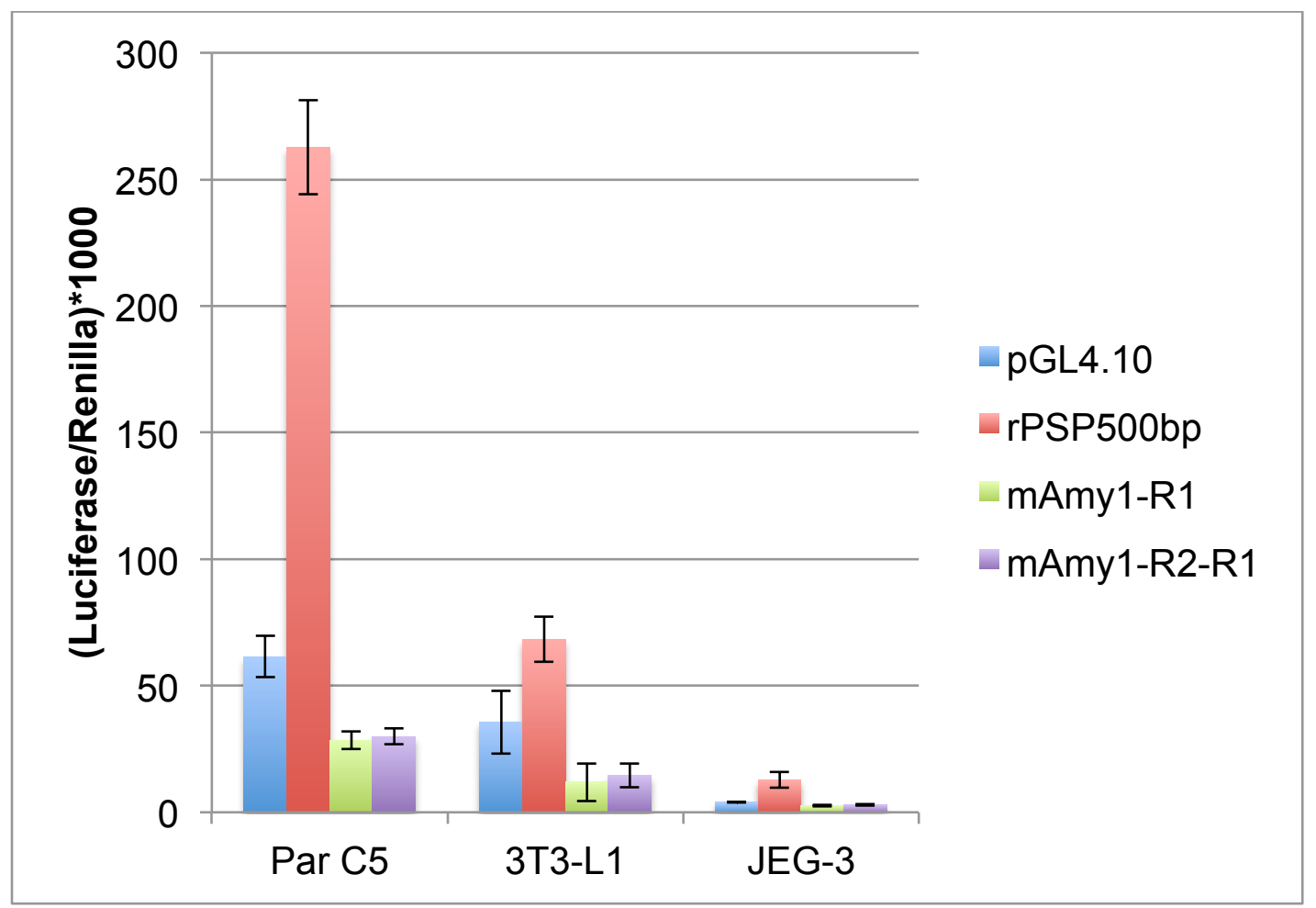

Figure 5: Testing the activity of mouse amylase R1 and mouse amylase R2-R1 promoter. The activity of mouse amylase I promoter is compared to a promoterless negative control, pGL4.10, and a positive control rat PSP 500 bp promoter. Each cell line demonstrates low activity of the amylase I promoters. For each cell type, $\mathrm{N}=1$ independent experiment with triplicate wells. 
Figure 6: Activity of mouse and rat amylase I promoter with repressors removed in different cell lines.

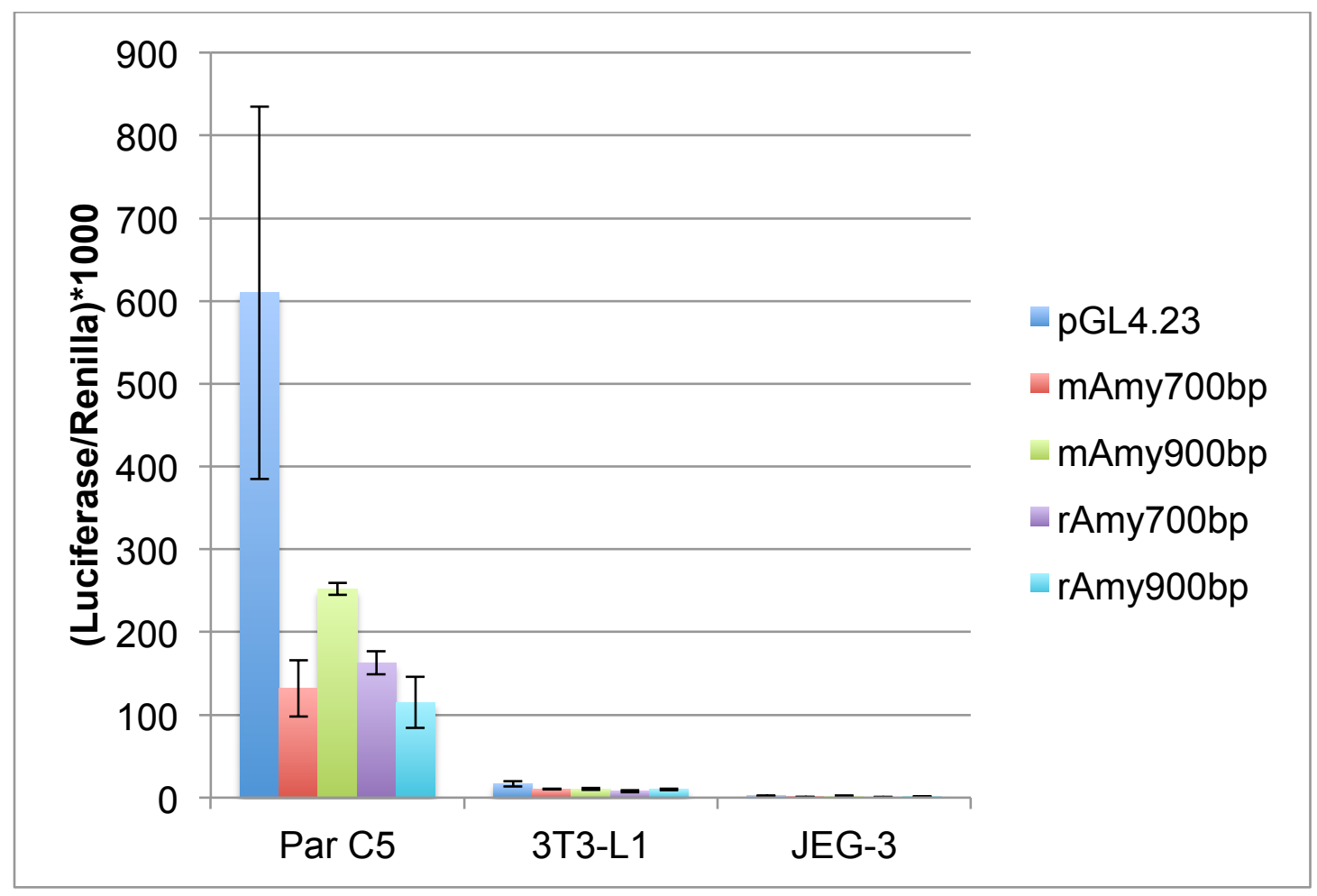

Figure 6: Testing the activity of mouse amylase 900 bp promoter and mouse amylase $700 \mathrm{bp}$ promoter. The activity of mouse amylase I promoter is compared to a negative control, pGL4.23. The activity of the amylase I promoters is still very low when transcriptional repressor binding sites are removed in three different cell lines. For each cell type, $\mathrm{N}=1$ independent experiment with triplicate wells. 


\section{CHARACTERIZING THE NUPR1 PROMOTER REGION}

The next goal was to characterize the NUPR1 promoter by testing the predicted regulatory interactions of this gene. The NUPR1 promoter clone used in the following experiments contains a 1305 bp proximal promoter region directing expression of luciferase (Figure 7). Cited2 + p300 and IRF2 + PCAF were predicted to stimulate gene expression based on the hypothetical network described above (Figure 2). The NUPR1 promoter clone was co-transfected with Cited2 + p300 into ParC10 and 3T3-L1 cell lines. The promoter was also cotransfected with IRF2 + PCAF in 3T3-L1 cells. Luciferase and renilla assays were performed to test promoter activity. NUPR1 promoter activity was determined by normalizing luciferase to renilla.

The NUPR1 promoter was not active in the ParC10 cell line (Figure 8A). The promoter activity was only a little higher than the promoterless pGL4.10 negative control, but not high enough to confirm its activity in ParC10 cells. Even though the promoter was inactive, it was analyzed using ANOVA and no significant change in NUPR1 promoter activity was found when Cited $2+p 300$ cDNAs were co-transfected in ParC10 cells $(p=0.0961)$.

The NUPR1 promoter was active when transfected in the 3T3-L1 cell line. A one-tailed T-test calculated a significant increase in promoter activity when comparing the promoterless pGL4.10 negative control to the NUPR1 promoter, $p$ $=0.05$. A one-tailed T-test determined no significant change in NUPR1 promoter activity when Cited2 + p300 were co-transfected, $p=0.2058$ (Figure 8B). 
The second interaction tested was the effect of IRF2 + PCAF transcription factors on NUPR1 promoter activity. Again, the NUPR1 promoter exhibited higher activity than the promoterless pGL4.10 negative control in 3T3-L1 cells (Figure 9). However, the ANOVA calculated a non-significant change in NUPR1 promoter activity when IRF2 + PCAF are co-transfected in 3T3-L1 cells, $p=$ 0.1409. The conclusion from this data is the NUPR1 promoter is not being activated by either Cited $2+$ p300 or IRF2 + PCAF in two different cell lines; therefore, the data do not support the hypothetical transcription factor network. 
Figure 7: NUPR1 promoter clone

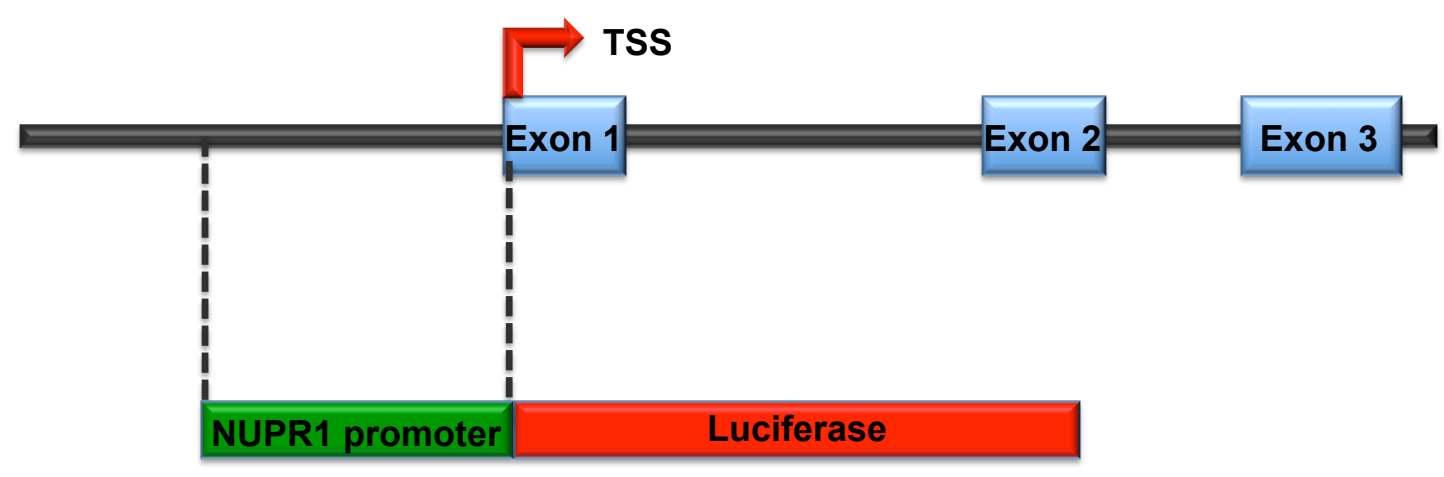

Figure 7: A picture representing the NUPR1 gene and promoter region. The transcription start site and the three exons of the NUPR1 gene are shown. The 1305 bp promoter was ligated into the pGL4.10 luciferase vector. 
Figure 8: Effect of Cited2 + p300 on NUPR1 promoter activity in ParC10 and 3T3-L1 cell lines.

\section{A. ParC10 cells}

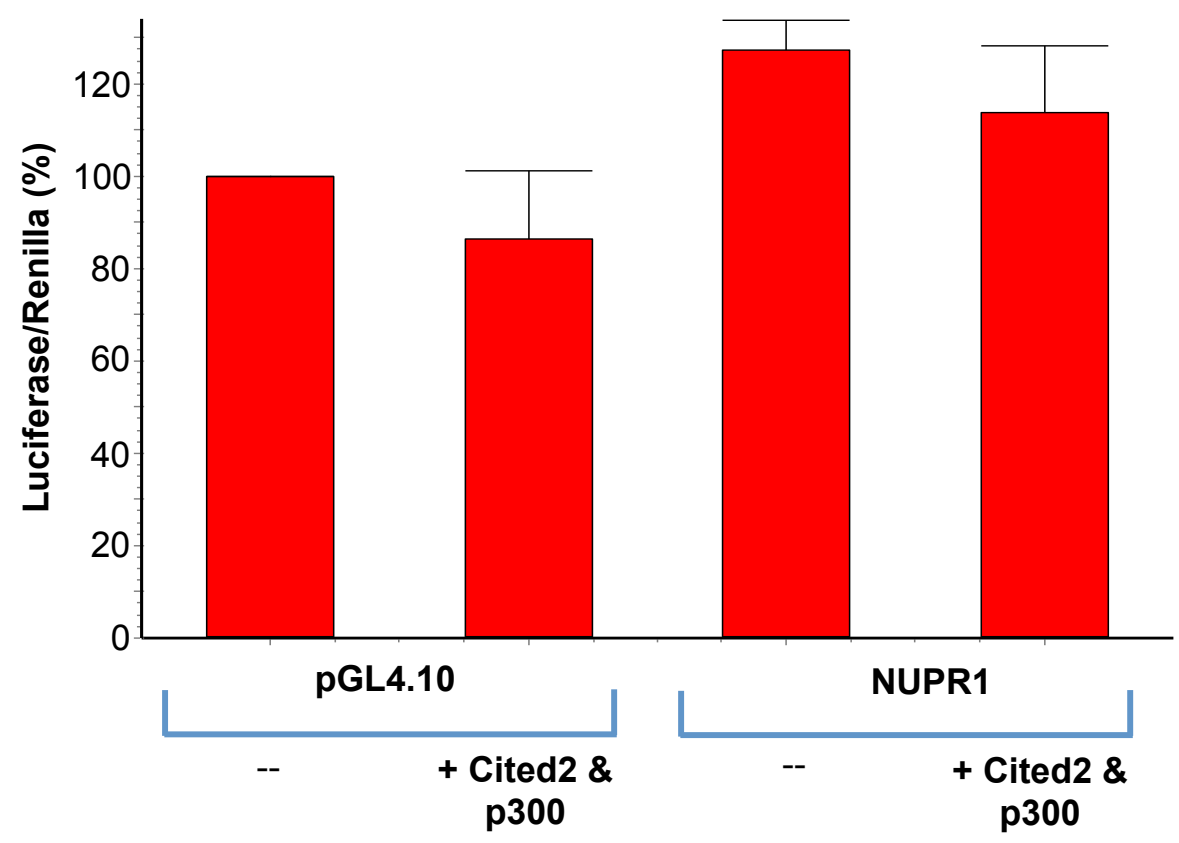

B. 3T3-L1 cells

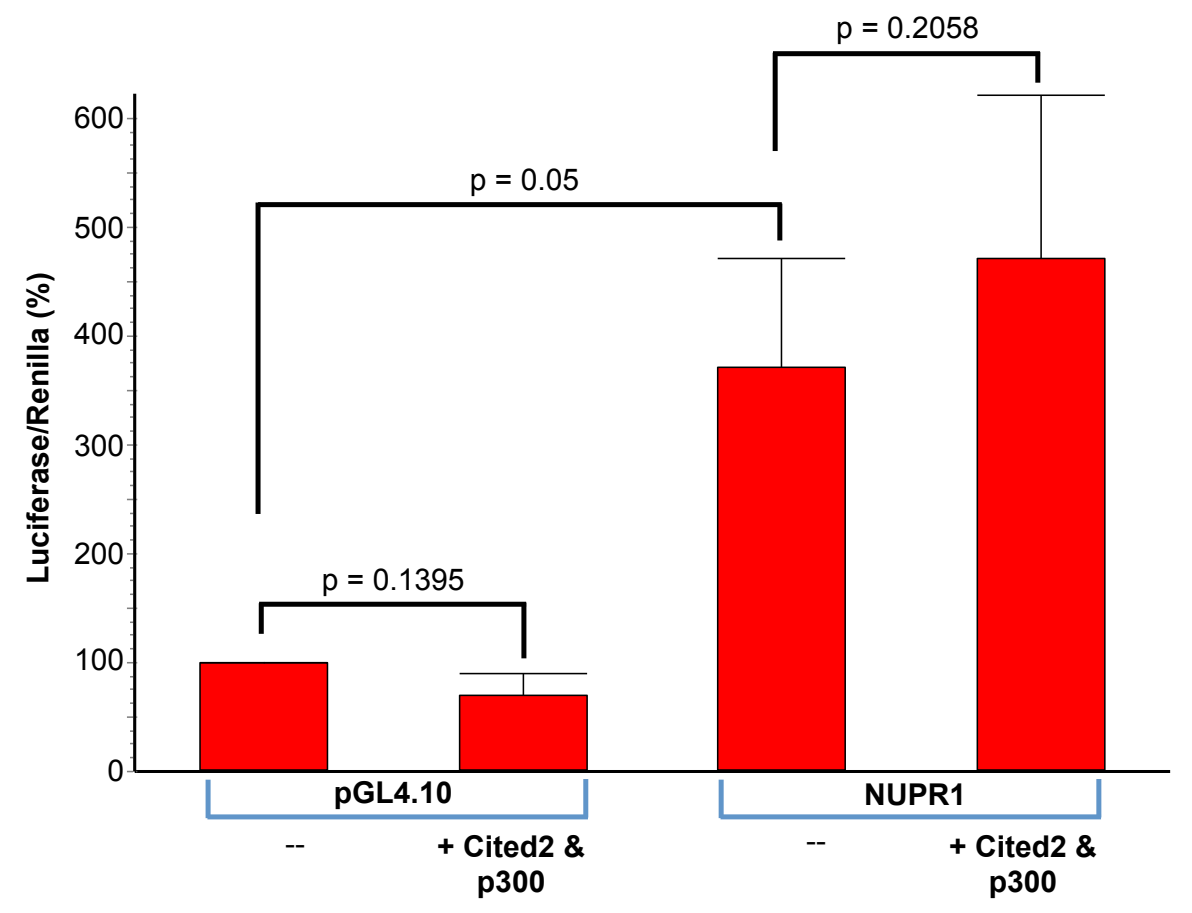


Figure 8: A: The NUPR1 promoter clone was co-transfected with Cited2 + p300 expression plasmids into ParC10 cells. Promoter activity was determined by normalizing raw luciferase to raw renilla luciferase values. ANOVA did not show any significant changes between any of the groups, $p=0.0961$. Therefore, Cited2 + p300 do not activate NUPR1 promoter in ParC10 cells. The pGL4.10 control was set to $100 \% . N=4$ independent experiments done with triplicate wells. B: The NUPR1 promoter clone alone was activated in 3T3-L1 cells and a Mann-Whitney one-tailed t-test calculated a significant activation, $p=0.05$. The NUPR1 promoter clone was co-transfected with Cited $2+$ p300. One-tailed T-test of NUPR1 calculated a p-value that is not significant. This statistical analysis proves NUPR1 promoter is not activated by Cited $2+$ p300 in 3T3-L1 cells. The pGL4.10 control was set to $100 \% . N=3$ independent experiments done with triplicate wells. 
Figure 9: Effect of IRF2 + PCAF on NUPR1 promoter activity in 3T3-L1 cells.

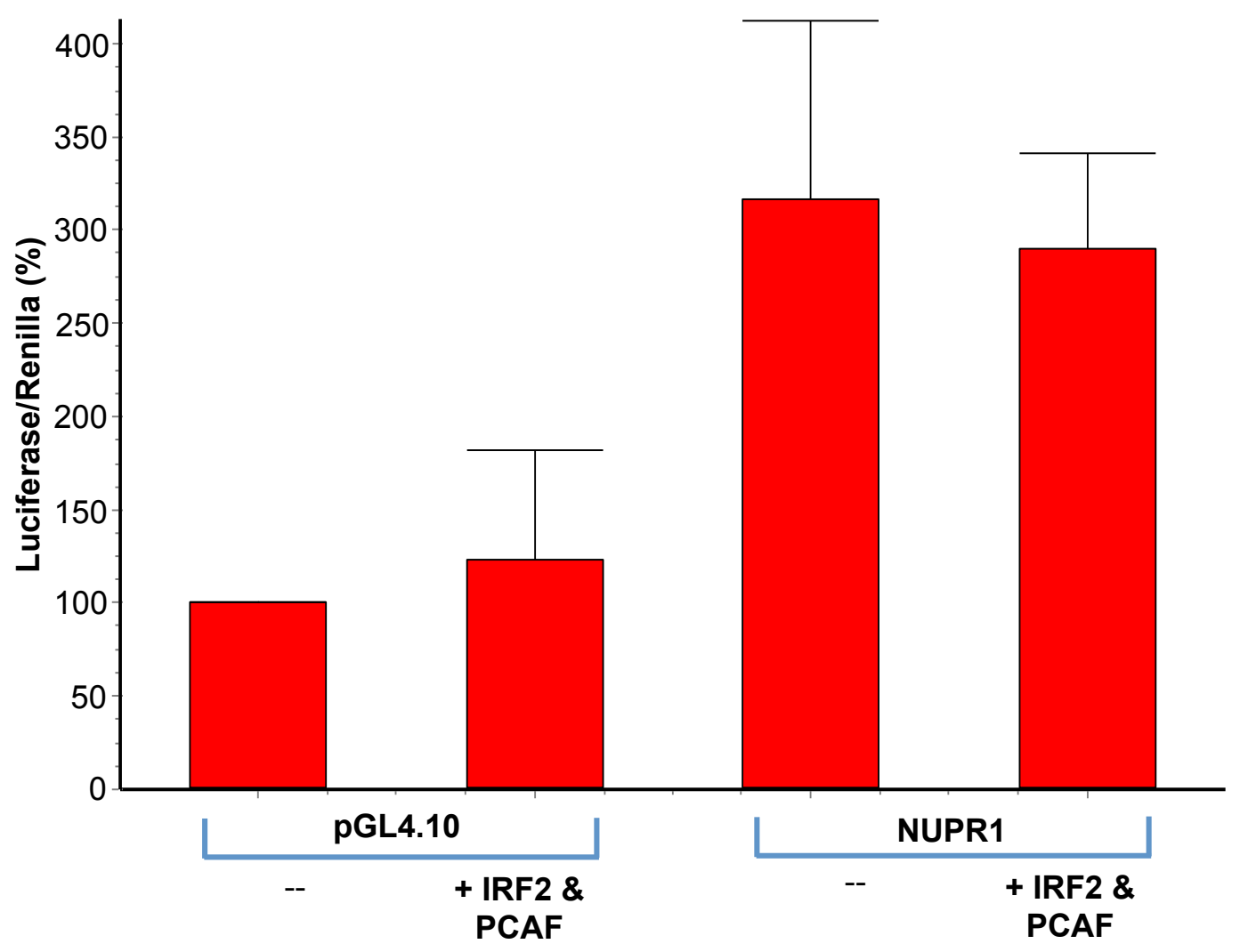

Figure 9: The NUPR1 promoter-luciferase clone was co-transfected with IRF2 + PCAF cDNAs in 3T3-L1 cells. Promoter activity was determined by normalizing raw luciferase to raw renilla luciferase values. ANOVA did not show any significant changes between any of the groups, $p=0.1409$. Therefore, IRF2 + PCAF do not activate NUPR1 promoter in 3T3-L1 cells. The pGL4.10 control was set to $100 \% . N=2$ independent experiments done with triplicate wells. 


\section{CHARACTERIZING PSP PROMOTER REGION}

Parotid secretory protein (PSP) is an abundant protein in saliva and has been suggested to have antibacterial properties that protect the oral cavity. Research has focused on PSP protein function, but much work remains to be done to characterize PSP gene regulation. The PSP gene is a marker of parotid differentiation and contains regulatory regions in its promoter region that need to be characterized. One transcription factor that was identified in the hypothetical transcription factor network was Mist1, and it was predicted to act on PSP (Figure 2). Mist1 is a transcriptional activator that binds the E-box motif CANNTG, and these sites were identified in the rat PSP promoter region. The first goal was to determine if Mist1 activates the rat PSP $2 \mathrm{~kb}$ promoter region. The second goal was to determine if mutating E-box DNA binding sites in the rat PSP 2kb promoter would prevent activation.

The rat PSP promoter clones, non-mutated and mutated, are depicted in Figure 10 and Figure 11. The non-mutated PSP promoter clone was previously made in the laboratory and contains a 2,000 bp proximal promoter region next to the transcription start site of the PSP gene. The region was PCR amplified and then ligated into a pGL4.10 luciferase vector. The correct sequence was confirmed, the DNA was purified, and transfection experiments were performed to test promoter activity.

In addition, sequence analysis found E-box sites, or Mist1 binding sites, in the pGL4.10 luciferase vector and in the 2,000 bp promoter region (Figure 11). These sites were mutated following the recommended protocol in the 
QuikChange II Site-directed Mutagenesis Kit provided by Stratagene. The correct sequence was confirmed, the DNA was purified, and transfection experiments were performed to test promoter activity. The non-mutated and mutated promoter DNA clones were co-transfected with rat Mist1 cDNA in ParC10 cells. The cell lysates were tested for promoter activity and transfection efficiency by luciferase assays and renilla luciferase assays, respectively.

The data show that the non-mutated PSP $2 \mathrm{~kb}$ promoter and the mutant clones, PSP2kb-pGL4.10 ${ }^{\Delta \mathrm{M}}$ and PSP2kb ${ }^{\Delta \mathrm{M}}$-pGL4.10 ${ }^{\Delta \mathrm{M}}$, were active in ParC10 cells (Figures 10 and 11). Samples co-transfected with Mist1 had repressed activity (Figure 12). The promoter activity was repressed by at least one-half or more when Mist1 was co-transfected as compared to the promoter activity without Mist1 co-transfected. Two-tailed T-test calculated nonsignificant repression for PSP2kb-pGL4.10 ${ }^{\triangle M}(p=0.1230)$ and significant repression for PSP2kb ${ }^{\Delta M}$-pGL4.10 ${ }^{\Delta M}(p=0.0132)$. The two-tailed T-test for the non-mutated PSP $2 \mathrm{~kb}$ promoter did not calculate a significant repression $(p=0.0822)$, but promoter activity appears to decrease by about one-half when Mist1 is cotransfected as compared to the control PSP $2 \mathrm{~kb}$ promoter. Based on these results, Mist1 alone does not activate the PSP gene through the promoter region; therefore, this does not support the hypothetical network of Mist1 activating PSP through the promoter region.

Mist1 can activate gene expression by binding as a heterodimer with another bHLH protein. Tcf3, or E2A, has been shown to bind DNA as a heterodimer with Mist1 and bind E-box sites [84]. The first goal was to 
demonstrate that a combination of Mist1/Tcf3 transcription factors did not activate the PSP promoter. This goal was achieved by co-transfecting a combination of rat Mist1 cDNA and rat Tcf3 cDNA with the rat PSP $1.5 \mathrm{~kb}$ promoter construct (Figure 10) in the ParC10 cell line. The results from this data observe no change in promoter activity (Figure 14). A one-tailed T-test calculated a p-value of 0.1735 , indicating there was no effect of the Mist $1 /$ Tcf 3 transcription factor combination. This result supported the hypothesis that the combination of Mist1 and Tcf3 transcription factors does not activate the PSP promoter region. 
Figure 10: rat PSP gene with indicated promoter clone constructs.

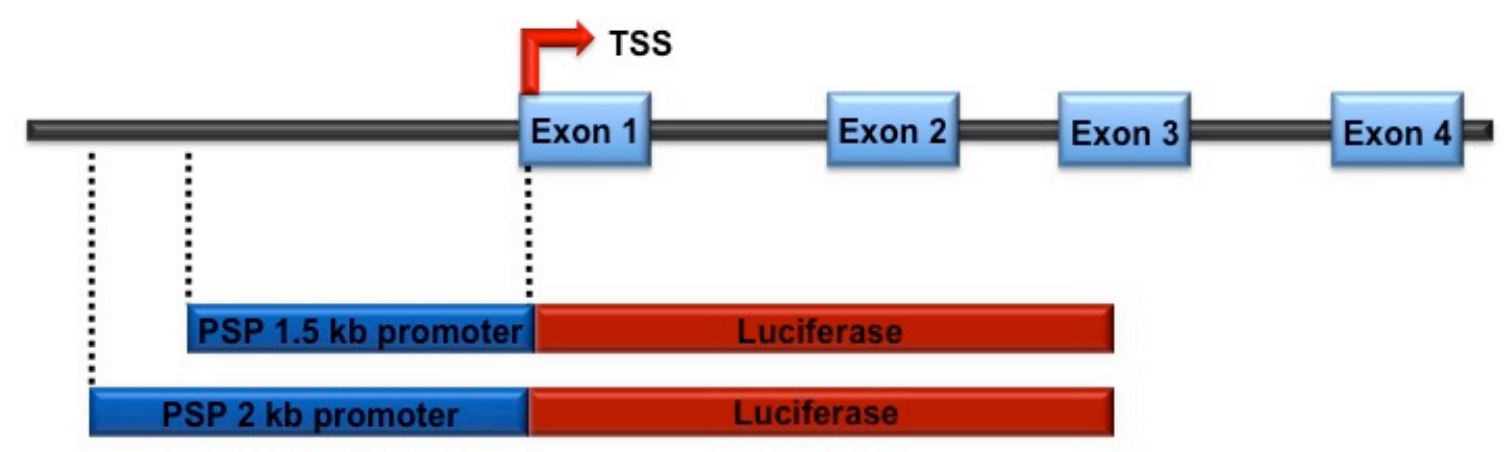

Figure 10: A diagram of the PSP gene. Exons 1-4 are labeled and the red arrow indicates the transcription start site. The PSP 1,500 bp promoter and the PSP 2,000 bp promoter constructs are shown ligated to a pGL4.10 luciferase vector. The PSP 2,000 bp promoter clone was used in co-transfection experiments with Mist1 transcription factor. 
Figure 11: rat PSP 2kb promoter construct with E-box binding sites for mutagenesis.
A. PSP2kb-pGL4.10 $1 \mathrm{M}$

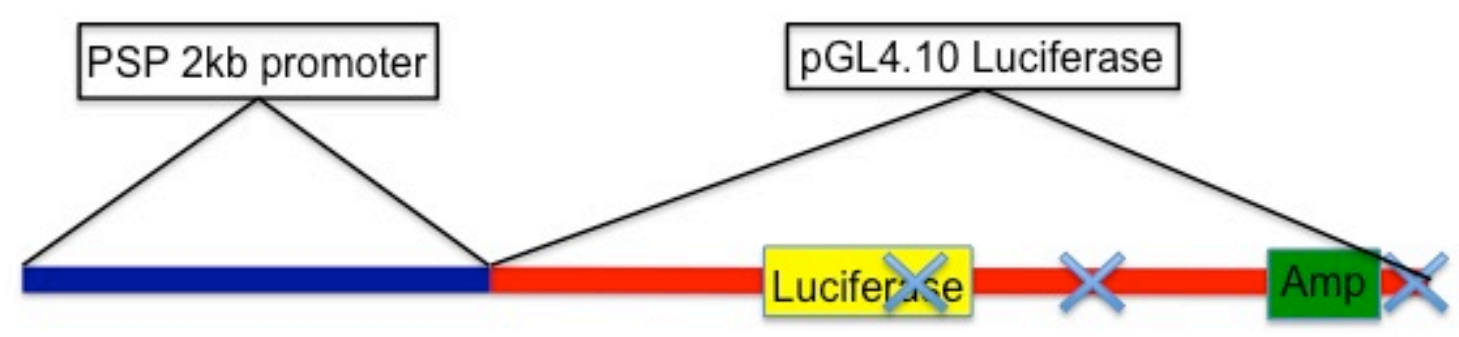

B. PSP2kb ${ }^{\Delta M}-$ pGL4.10 ${ }^{\Delta M}$

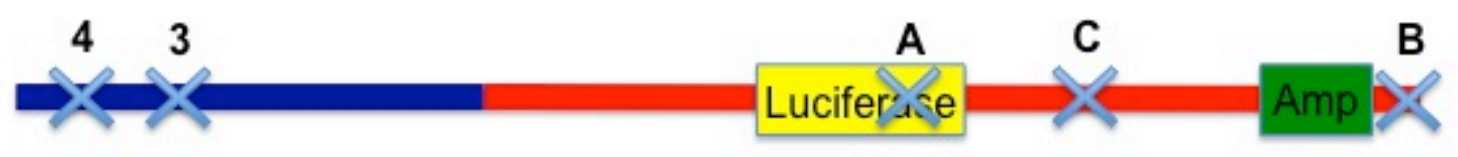

Figure 11: A diagram of the PSP 2kb promoter ligated in pGL4.10 luciferase vector. The consensus E-box DNA site mutated in these clones is CANNTG. Sites $A, B$, and $C$ are located in pGL4.10 and sites 3 and 4 are located in PSP 2kb promoter. A: The PSP2kb-pGL4.10 ${ }^{\Delta M}$ clone has E-box sites A, B, and C mutated in the pGL4.10 luciferase vector, and the PSP $2 \mathrm{~kb}$ promoter fragment is ligated to this mutated vector. B: The PSP2kb $\mathrm{kg}^{\Delta \mathrm{M}}-\mathrm{pGL} 4.10^{\Delta \mathrm{M}}$ clone has E-box sites A, B, and C mutated in the pGL4.10 luciferase vector, and E-box sites 3 and 4 are mutated in the PSP $2 \mathrm{~kb}$ promoter region. 
Figure 12: Testing the effect of Mist1 on non-mutant and E-box mutant PSP promoter.

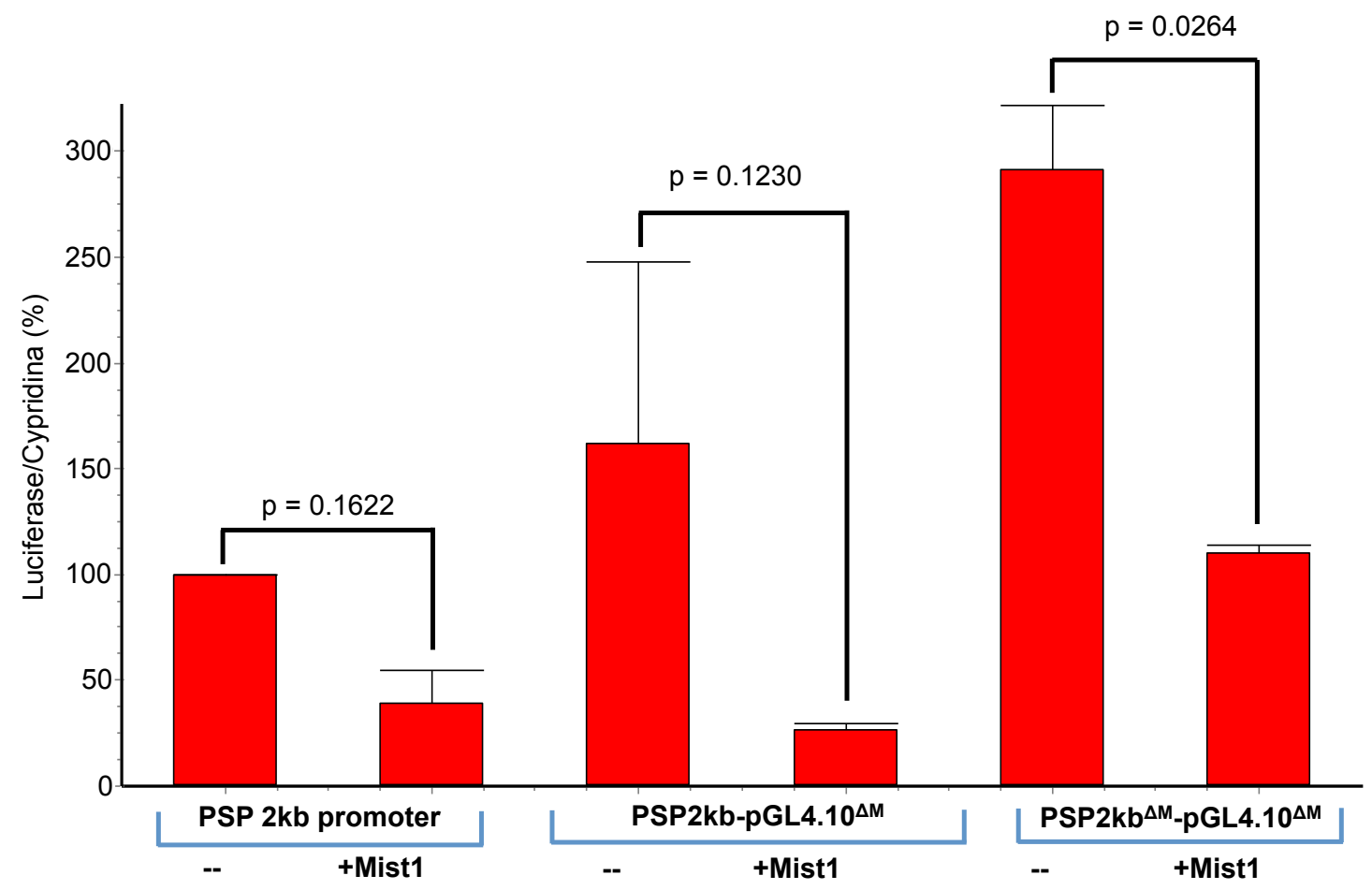

Figure 12: Non-mutated PSP promoter and E-box mutated PSP promoter activity by Mist1. Promoter activity is measured by the percent luciferase:cypridina ratio and compared to non-mutated PSP promoter activity (set to $100 \%)$. ANOVA found significant changes in the data $(p=0.0205)$, so twotailed paired T-tests were performed to distinguish changes in promoter activity when Mist1 was co-transfected. $\mathrm{N}=2$ independent experiments done with triplicate wells. 


\section{CHARACTERIZATION OF PSP PROMOTER + INTRON REGION}

Mist1 did not activate the PSP proximal promoter, so I investigated another way this gene may be activated by Mist1. Mist1 has been shown to activate gene expression by binding to E-box sites in the first intron of genes [48]. The next goal was to determine if a combination of Mist1/Tcf3 transcription factors activate PSP through intron regions of the gene. Sequence analysis of the rat PSP gene, exons and introns, found E-box binding sites in the second, third, and fifth introns (Figure 13). The region between exon 2 and exon 4 was successfully PCR amplified. This region contains E-boxes in the second and third introns. Amplifying the region containing E-box sites in the fifth intron was unsuccessful, so attempts to make this clone were halted. The intronic amplified region was digested with Sall restriction enzyme, and the PSP $1.5 \mathrm{~kb}$ promoter clone was digested with Xhol restriction enzyme. When the intronic region was ligated into the PSP $1.5 \mathrm{~kb}$ promoter clone, the Sall sites and the Xhol sites at the cloning region were abolished. The only issue with cloning with these enzymes was the risk that the intronic region would be ligated in the opposite orientation; however, DNA sequence analysis confirmed a clone that contained the inserted region in the correct, or forward, orientation. After sequence confirmation, this clone was purified and used in transfection experiments.

A combination of rat Mist1 cDNA and rat Tcf3 cDNA was co-transfected with the PSP promoter + intron clone into ParC10 cells. This experiment was done simultaneously when testing the effect of Mist1 and Tcf3 on the PSP $1.5 \mathrm{~kb}$ promoter. Performing these experiments in unison resulted in the PSP $1.5 \mathrm{~kb}$ 
promoter to be used as a good negative control to compare to the PSP promoter + intron results. The results from testing the effect of the transcription factor combination determined that PSP promoter + intron activity is increased by about 2-fold (Figure 14). A one-tailed T-test calculated a significant change in PSP promoter + intron activity when Mist $1 /$ Tcf3 was co-transfected, $p=0.0136$. These results conclude that PSP can be activated through the second and third intron regions by a combination of Mist $1 /$ Tcf3. This conclusion supports the hypothesis that a Mist1/Tcf3 combination can activate PSP through intronic binding sites.

The next goal was to determine if there is a specific effect from Mist1 alone or Tcf3 alone. ParC10 cells were transfected with PSP $1.5 \mathrm{~kb}$ promoter or PSP promoter + intron and Mist1 alone, Tcf3 alone, or a Mist1/Tcf3 combination. Luciferase assay RLU values were normalized to Cypridina RLU values to determine promoter activity. ANOVA of PSP $1.5 \mathrm{~kb}$ promoter group was significant, $p=0.0001$ (Figure 15). Mann Whitney two-tailed T-test comparing the control, PSP $1.5 \mathrm{~kb}$ alone, to the different experimental groups was performed. There was no change in promoter activity by Tcf3 when compared to the negative control, promoter alone, and the T-test calculated the effect of Tcf3 alone was not significant, $p=0.3429$. Mist1 repressed promoter activity, and this repressive effect of Mist1 was significant, $p=0.0286$. The combination of Mist1/Tcf3 repressed the promoter as well, and the repression by Mist1/Tcf3 was significant as calculated by the T-test, $p=0.0286$. As observed above, the effect of Mist1 and the combination of Mist1/Tcf3 repressed transcription from the PSP $1.5 \mathrm{~kb}$ promoter, and transfection of Mist1 alone is sufficient for repression. 
A Mann-Whitney test using a two-tailed T-test was used to test significance between the control group, PSP promoter + intron without Mist1, Tcf3, or the combination, and the experimental groups. The effect by Tcf3 alone appeared to increase luciferase activity, but the Mann-Whitney test calculated a non-significant $p$-value for the effect of Tcf3 on PSP promoter + intron $(p=$ 0.3429). Mist1 did not change PSP promoter + intron activity, and the MannWhitney test calculated $p>0.9999$ for the effect of Mist1 on PSP promoter + intron. However, PSP promoter + intron co-transfected with the combination of Mist1/Tcf3 exhibited a dramatic increase in activity, and had a significant $p$-value from the Mann-Whitney two-tailed T-test, $p=0.0286$ (Figure 15). Based on this data there is not a specific effect from Mist1 alone or Tcf3 alone on PSP promoter + intron activity. This data further confirms results that a combination of Mist1 and Tcf3 activates PSP through the second and third intron regions. The data support the hypothetical network that Mist1 does interact with PSP. The novelty of this interaction is that Mist1 activates PSP when the E-box protein Tcf3 is present, and activation by Mist1 can be through the intron regions of the PSP gene. 
Figure 13: PSP promoter + intron clone

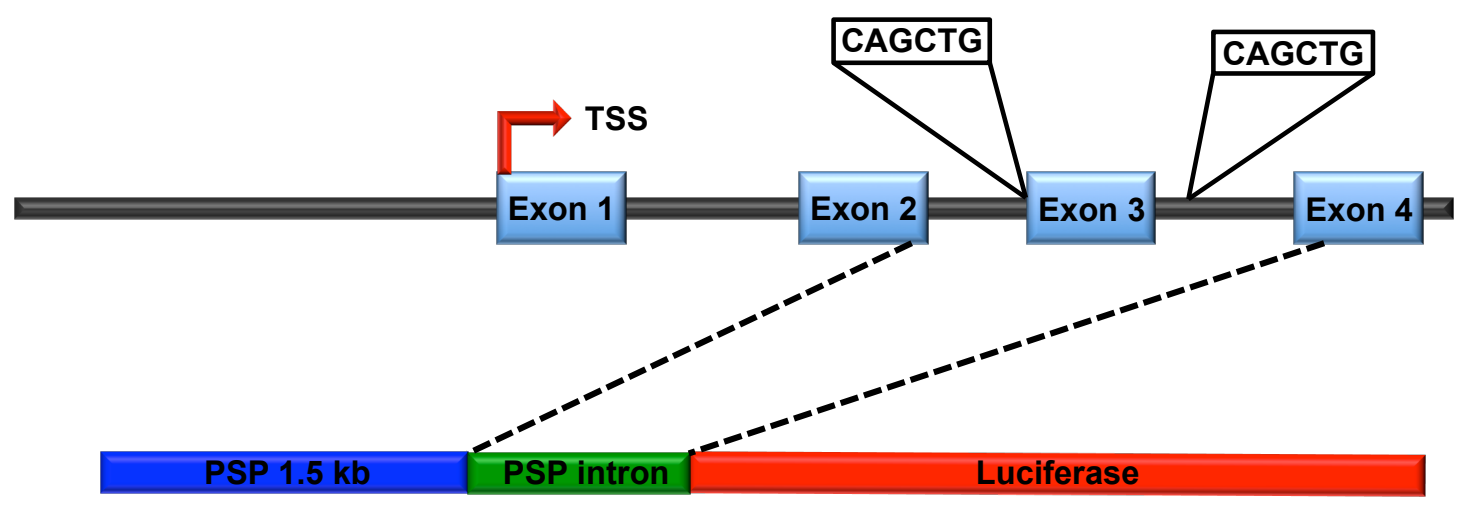

Figure 13: The top of the figure shows the first four exons (labeled 1 - 4

underneath) and the first three intron regions of the PSP gene. The E-box

binding sites in the intronic regions are labeled. The bottom of the figure is the

PSP promoter + intron clone used in transfection experiments. The dotted lines

indicate the PSP intron region that was amplified from rat genomic DNA. The

intronic region was ligated into the PSP $1.5 \mathrm{~kb}$ promoter clone depicted in figure 10. 
Figure 14: Testing the effect of Mist1/Tcf3 combination on PSP promoter and PSP promoter + intron activity.
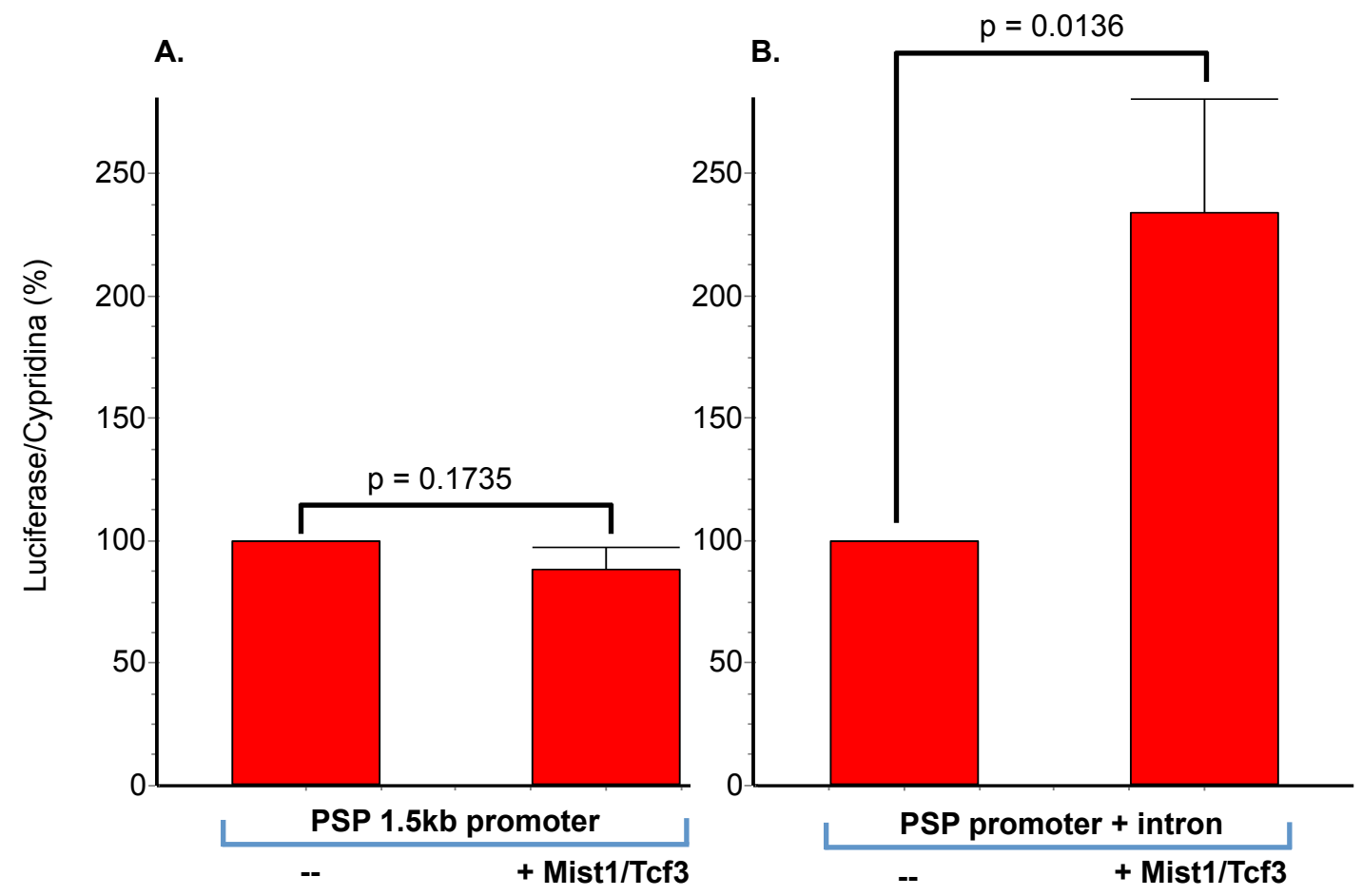

Figure 14: A: PSP $1.5 \mathrm{~kb}$ promoter activity without and with Mist1/Tcf3 cotransfected in ParC10 cells. Promoter activity was measured as the percentage of luciferase/cypridina. The promoter alone was set at 100 and compared to the promoter co-transfected with the Mist1/Tcf3 combination. There was no change in promoter activity from the Mist1/Tcf3 combination and, a one-tailed T-test calculated an insignificant change in promoter activity, $p=0.1735$. B: PSP promoter + intron without and with a Mist1/Tcf3 combination co-transfected in ParC10 cells. Promoter + intron activity was measured as the percentage of luciferase/Cypridina. The PSP promoter + intron alone was set to 100 and compared to the promoter + intron co-transfected with a Mist1/Tcf3 combination. The promoter + intron activity increased almost two-fold, and a one-tailed T-test 
calculated a significant change in activity, $\mathrm{p}=0.0136 . \mathrm{N}=7$ independent experiments done with triplicate wells for both $A$ and $B$. 
Figure 15: Testing the specific effect of Tcf3 alone or Mist1 alone on PSP promoter + intron activity.

A.

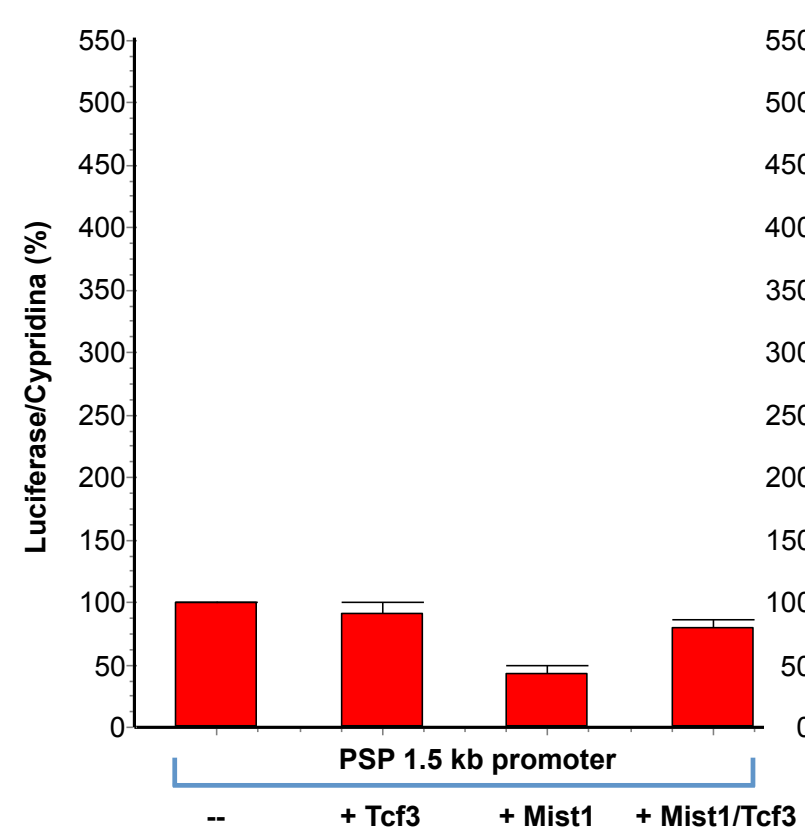

B.

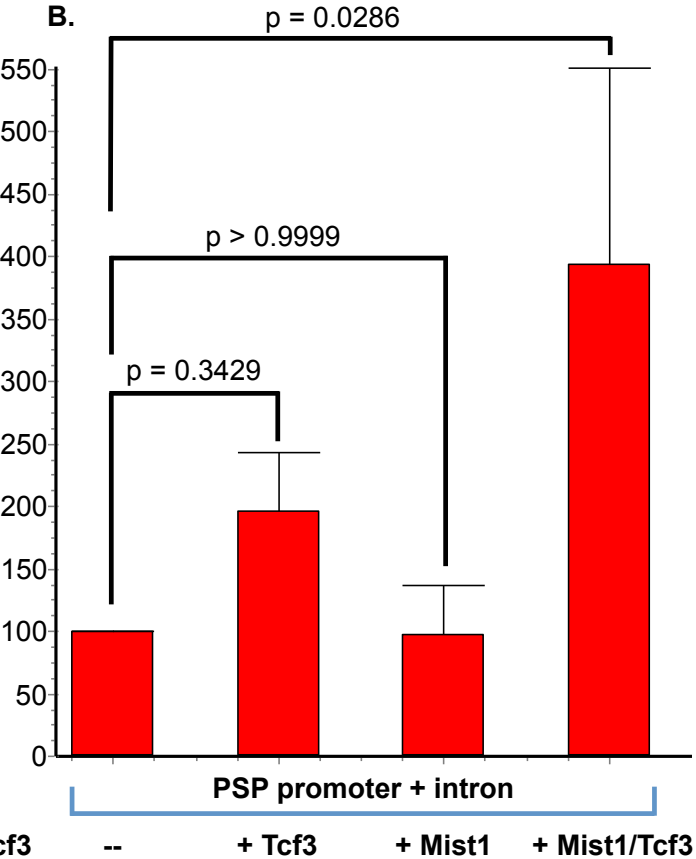

Figure 15: A: PSP $1.5 \mathrm{~kb}$ promoter activity without any transcription factor and with Tcf3 alone, Mist1 alone, or a Mist1/Tcf3 combination. The control group, promoter alone, was set to 100 and each experimental group was compared to this control. ANOVA calculated significant changes among the group, $p=0.0001$. Mann-Whitney two-tailed T-test was calculated between the control and individual experimental groups. Tcf3 did not have an effect on the promoter, $p=$ 0.3429. Mist1 alone and the Mist1/Tcf3 combination had significant repressive effects on the promoter, $p=0.0286$ for both. B: PSP promoter + intron activity without any transcription factor and with Tcf3 alone, Mist1 alone, or a Mist1/Tcf3 combination. The control group, promoter + intron alone, was set to 100 and each experimental group was compared to this control. A Mann-Whitney twotailed T-test calculated a significant change when a combination of Mist1/Tcf3 is 
co-transfected with PSP promoter + intron, $\mathrm{p}=0.0286 . \mathrm{N}=4$ independent experiments done with triplicate wells for both $\mathrm{A}$ and $\mathrm{B}$. 


\section{DISCUSSION}

\section{MOUSE AMYLASE 1 PROMOTER IS INACTIVE IN DIFFERENT CELL TYPES}

Salivary amylase is an abundant enzyme produced primarily from serous cells of the parotid that hydrolyzes food starch into maltose and glucose [32, 33]. Salivary amylase affects oral biofilms and is a component of the acquired enamel pellicle (AEP) $[34,36,37]$. Amylase has two genes located on mouse chromosome three $[25,26]$. The first locus corresponds to Amy-1, which is expressed in the salivary gland, and the second locus is Amy-2, which is expressed in the pancreas. The Amy-1 gene is expressed as two different mRNA products with one in the parotid gland and the other in the liver. Amy-1 has two promoters with tissue specific expression in the parotid gland and in the liver [28]. Testing endogenous promoter activity and measuring amylase mRNA levels determined the location of the parotid and liver promoters and their activity [26, 28, 31].

Stable and transient transfection experiments performed in cell lines lacking endogenous Amy-1 observed that the $P_{L}$ was active in all cell types, but that the $P_{P}$ did not show activation in any of the cell types tested [28]. In an isolated comment about unpublished data it was claimed that deletion of the 5' flanking region of $\mathrm{P}_{\mathrm{P}}$ observed that removing nucleotides upstream of position 300 relieved transcriptional repression. 
The amylase parotid promoter region was determined by analysis of the mRNA start sites, but little work has been done to characterize this region. The lack of research defining the regulatory regions of amylase is surprising because amylase is one of the major proteins in saliva and is a terminal differentiation marker of the parotid gland [30]. The goal of this research was to determine transcriptionally active promoter regions. Clones were made and tested in transient transfection, which experiments contained up to $3 \mathrm{kbp}$ of the amylase parotid-specific promoter. Two clones were made and tested that had transcriptional repressor binding sites removed from the 5 ' end of the $1 \mathrm{~kb}$ proximal promoter region. Each amylase promoter clone was transfected in three different cell lines, ParC5, 3T3-L1, and JEG-3.

All amylase parotid promoter clones were repressed compared to the promoterless negative control, pGL4.10, in each cell line. The repression of the $1 \mathrm{~kb}$ proximal promoter was expected because Schibler et. al. observed the same result. The idea that activating elements could be further upstream from a proximal promoter led to cloning an additional $2 \mathrm{kbp}$ region upstream of the proximal promoter. Again, adding this $2 \mathrm{kbp}$ promoter region did not activate amylase in any cell type this clone was transfected in. The results from testing the $900 \mathrm{bp}$ and $700 \mathrm{bp}$ promoter clones also exhibited repression in all cell types. This was unusual because removing transcriptional repressor sites from the region should relieve any repressive effects. The amylase promoter was repressed in multiple cell types even after testing a region upstream of the suggested proximal promoter region and by removing transcriptional repressors. 
The conclusion from these amylase 1 experiments is that amylase is being activated by another region outside of the $3 \mathrm{~kb}$ region tested or cryptic repressor binding sites are present within the smallest (700 bp) promoter tested. Future work cloning even further upstream regions might find an active promoter. Once an active region is found analysis can be performed to characterize and define transcriptional activators involved in amylase 1 activation.

\section{CONFIRMING TRANSCRIPTIONAL PATHWAYS IN THE HYPOTHETICAL TRANSCRIPTION FACTOR NETWORK OF PAROTID GLAND DIFFERENTIATION}

Many molecular mechanisms are involved in parotid gland differentiation, and the role of transcription factors was of interest in this research. Rat parotid gland mRNA was analyzed in the laboratory by Dr. Srirangapatnam, and the results showed that many transcription factors are tightly regulated during parotid gland differentiation. Testing mRNA from embryonic stages to postnatal stages determined that a single transcription factor could be expressed at variable levels throughout development. It appeared that related transcription factors were expressed at the same time point, and this allowed us to determine four distinct stages of differentiation. Each stage was examined to find transcription factors that had increased levels of expression as genes of interest increased expression levels. Once these patterns of expression were determined, the transcription factors and genes were entered into the IPA program to model 
predicted interactions [24]. A hypothetical transcription factor network of parotid gland differentiation was created using IPA (Figure 2).

The focus of the next part of my research was to validate some of the pathways of the hypothetical transcription factor network. One of the interactions tested was the effect of a combination of Cited2 and p300 co-factors and a combination of IRF2 transcription factor and PCAF co-factor on NUPR1 promoter activity. The other interaction tested was the effect of Mist1 transcription factor on PSP promoter activity. The goal was to confirm interactions by performing transient transfection experiments in parotid acinar cell types. Confirming interactions would also aid in characterizing the promoter regions of interest.

\section{NUPR1 PROXIMAL PROMOTER IS NOT ACTIVATED BY CITED2/P300 OR IRF2/PCAF COMBINATIONS}

The NUPR1 protein is a transcription factor that binds to DNA to regulate gene expression in the exocrine cells of various tissues such as the salivary glands, stomach, colon, liver, and kidneys [38-40]. NUPR1 was the first promoter tested from the hypothetical network. The goal was to validate two separate interactions with the NUPR1 promoter. These interactions included determining the effect of the combination of Cited 2 and p300 co-factors and the combination of IRF2 and PCAF on NUPR1 promoter activity. The hypothesis tested was that Cited2/p300 and IRF2/PCAF would activate the NUPR1 promoter. Confirming these transcription factor interactions would support the hypothetical transcription factor network of parotid differentiation. 
The first combination of co-factors tested to determine their effect on the NUPR1 promoter was Cited 2 and $p 300$. Cited2 belongs to a family of genes known as CITED (CBP/p300 interacting transactivators with ED-rich termini) [49, 50]. CITED proteins do not bind DNA, but serve as transcriptional co-activators. Cellular Cited2 binds tightly to the CBP/p300 transcription complex, and this interaction is predicted in the hypothetical network (Figure 6). The nuclear phosphoprotein, p300, is widely expressed and homologous to the cAMP response element binding protein (CBP), $[54,55]$. p300 is a co-activator that links DNA-bound transcriptional activators to the basal transcription machinery. It has histone acetyltransferase (HAT) activity that is involved in modifying chromatin structure within gene promoters, and the HAT activity allows p300 to increase DNA binding efficiency of p300-interacting transcription factors [56, 57]. Both of these histone-modifying actions result in more efficient transcription of target genes.

The effect of Cited2 and p300 on NUPR1 promoter was tested in two different cell lines. First, Cited2 and p300 were co-transfected with the NUPR1 promoter in ParC10 cells. The NUPR1 promoter alone was inactive in this cell line, so the effect of Cited2 and p300 could not be determined. The ParC10 cell line is an undifferentiated acinar cell type, so important regulators of NUPR1 gene expression might not be present [102]. After determining the NUPR1 promoter was inactive in ParC10 cells, Cited2 and p300 were co-expressed with the NUPR1 promoter in an alternative cell line, 3T3-L1. The NUPR1 promoter alone was active in the 3T3-L1 cell line, so all future experiments testing NUPR1 
promoter activity used these cells. Even though the promoter was active as compared to the promoterless negative control, pGL4.10, there was no effect of Cited2 and p300 on NUPR1 promoter activity. An example from the literature of Cited2 repressing gene expression is on the NF-kB gene [107]. One of the ways it represses NF-KB is by sequestering p300 and inhibiting it from binding p65, an important activator of NF-kB. A similar mechanism might be happening with Cited2 and p300 resulting in no change in activity, instead of repression, of the NUPR1 promoter. However, there are many more instances of Cited2 and p300 working to enhance gene expression, so these transcriptional co-factors appear to not be involved in NUPR1 expression. The conclusion from the results did not support the hypothetical transcription factor network that Cited2 and p300 activate the NUPR1 promoter.

The next combination of transcription factors tested was the effect of IRF2 and PCAF on NUPR1 promoter activity. IRF2 belongs to the interferon regulatory (IRF) transcription factor family and binds DNA through its $\mathrm{N}$-terminal domain $[62,67]$. IRF2 binds various DNA elements such as interferon responsive element (IRF-E), the interferon consensus sequence (ICS), and the positive regulatory domain I (PRDI) of the IFN- $\beta$ gene $[63,64,66]$. IRF2 can function as a transcriptional repressor or activator [65].

The transcriptional cofactor p300/CBP-associated factor (PCAF) functions as a co-activator of transcription, and it has histone acetyltransferase (HAT) activity [73-75]. PCAF has been shown to have various functions such as acting as a tumor suppressor and being involved in differentiation [73, 82]. IRF-2 
recruits PCAF to enhance its own binding to the ICS [83]. The direct interaction of IRF-2 and PCAF was shown to increase the histone $\mathrm{H} 4$ gene promoter activity. Since this promoter was activated by IRF-2 and PCAF, this supported testing the effect of these transcription factors on NUPR1 promoter expression.

IRF-2 and PCAF were co-transfected with the NUPR1 promoter in the 3T3-L1 cell line. As mentioned above, the NUPR1 promoter was active in this cell line as compared to the promoterless negative control, pGL4.10. However, coexpression of IRF2 and PCAF did not increase NUPR1 promoter activity. It has been noted in the literature that IRF2 is acetylated by PCAF in a growing cell type, and acetylation of IRF2 is required for promoter activation [108]. The 3T3L1 cells used in these experiments are an undifferentiated pre-adipocyte cell type. Since acetylation of IRF2 only happens in growing cells, this transcription factor might not be sufficiently acetylated by PCAF in the experiments testing NUPR1 promoter activity. Stimulating 3T3-L1 cells in future transfection experiments might exhibit NUPR1 promoter activation from IRF2 and PCAF.

\section{THE PSP PROXIMAL PROMOTER IS NOT ACTIVATED BY MIST1 TRANSCRIPTION FACTOR IN THE PARC10 CELL LINE.}

The next interaction tested to validate the hypothetical transcription factor network was the effect of Mist1 on the PSP promoter. PSP is highly expressed in acinar cells of the adult parotid gland [14]. Mist1 is a bHLH transcription factor expressed in many tissues that binds to E-box sequences, -CANNTG-, as a homodimer or heterodimer [84-86]. The hypothesis was Mist1 would activate the 
PSP promoter. The goals were to first test PSP promoter activation from cotransfection of Mist1 cDNA. The second goal was to mutate Mist1 binding sites, or E-box binding sites, in the PSP promoter to determine promoter activity.

There were two objectives for testing the effect of Mist1 on PSP promoter activity. The first goal was accomplished by co-transfecting PSP promoter DNA with Mist1 cDNA in ParC10 cells. The second goal was accomplished by mutating -CANNTG- E-box binding sites in the PSP 2kb promoter construct (Figure 11). The non-mutant and mutant constructs were co-transfected with Mist1 cDNA in ParC10 cells. The non-mutated PSP promoter and the E-box mutated PSP promoter constructs were all repressed by Mist1. One reason this repression might have happened is that Mist1 homodimers repress gene expression. An example is MyoD repression by Mist1 homodimers during myogenesis [109]. The Mist1 homodimer directly binds to E-box sequences in the MyoD promoter and subsequently represses gene expression. In the experiments testing PSP promoter activity, Mist1 does regulate the PSP promoter, but not in the expected direction. This may be one aspect of controlling the timing of PSP expression during development. The conclusion was the results do not support the hypothetical network that Mist1 activates the PSP promoter. This conclusion led us to determine other ways Mist1 could be activating PSP.

\author{
PSP IS ACTIVATED BY A COMBINATION OF MIST1 AND TCF3 \\ TRANSCRIPTION FACTORS THROUGH THE SECOND AND THIRD INTRON
}


As mentioned above, Mist1 repressed the PSP promoter, and the repression might have been due to formation of Mist1 homodimers. In contrast to this finding, Mist1 has been reported to activate genes by forming heterodimers with the E-box protein Tcf3, or E2A [84]. The E2A gene encodes two class I bHLH transcription factors, E12 and E47, and binds E-box consensus sequences as does Mist1 transcription factor [84-86, 95]. The E2A transcription factor is expressed in various tissues and can act as a transcriptional activator or repressor depending on its binding partner and other co-activators or corepressors [86]. The finding that Mist1 and Tcf3 can form heterodimers led to the hypothesis that co-transfecting a combination of Mist1 and Tcf3 will activate the PSP promoter.

To test the hypothesis, transient transfection experiments were performed testing the effect of the combination of Mist1 and Tcf3 transcription factors on PSP promoter activity in ParC10 cells. The PSP promoter was not activated by the combination of transcription factors. The conclusion from this result was Mist and Tcf3 are not acting through the promoter region of PSP. Again, PSP is not exhibiting activation even though Mist1 has a dimerization partner that has been shown to activate gene expression. The next step was to find another way to express the PSP promoter.

One group found the gene Mindbomb-1 was activated by Mist1 through the first intron [48]. The PSP gene was analyzed and E-box binding sites were found in the second, third, and fifth introns of PSP. The evidence that Mist1 activates a gene through the first intron, and the analysis of the PSP gene helped 
formulate the hypothesis that a Mist1 and Tcf3 transcription factor combination activates PSP through the intron regions. The PSP promoter + intron clone was made by ligating a PCR amplified region between exon two and four into the PSP $1.5 \mathrm{~kb}$ promoter clone (Figures 10 \& 13). This clone was co-transfected with Mist1 and Tcf3 cDNA in ParC10 cells, and promoter + intron activity was determined by performing luciferase and cypridina assays. The data observed an increase in PSP promoter + intron activity when Mist and Tcf3 were cotransfected. The hypothetical network was supported by this result. A novel discovery from this result was Tcf3 interacts with Mist1 to activate the PSP promoter. This hypothetical network did not predict this interaction, and the conclusion was that Mist1 required Tcf3 to promote PSP gene expression.

Since the combination of Mist1 and Tcf3 promoted PSP expression, the next goal was to test the specific effect of Mist1 alone and Tcf3 alone. The PSP $1.5 \mathrm{~kb}$ promoter without the intron region was used as a negative control in these experiments because it was found to have no change in activity with a Mist1/Tcf3 combination. The promoter exhibited no change in activity from Tcf3 alone, which was a new finding, and from the combination of Mist1 and Tcf3, which was expected. Mist1 alone repressed PSP $1.5 \mathrm{~kb}$ promoter activity, which was consistent with the results described above. The results for the PSP $1.5 \mathrm{~kb}$ promoter made it a valid control to compare the effects on the PSP promoter + intron construct. The PSP promoter + intron was slightly activated by Tcf3 alone, but not significantly, and it exhibited no change in activity when Mist1 alone was co-transfected. Again, the PSP promoter + intron construct was activated by the 
combination of Mist1 and Tcf3 through the second and third introns, further supporting the hypothetical network with the new finding that Mist1 requires Tcf3 for PSP gene activation. The work reported that used a Mist1 knockout mice model supports the importance of Mist1 and the effect it has on secretory granule formation and the content of secretory granules [93, 94]. PSP is a protein found in parotid acinar cell secretory granules [102]. PSP activation by Mist1 could be happening just before or simultaneously with secretory granule formation, reiterating the importance of this transcription factor during parotid gland development.

\section{CONCLUSION}

Even though many interactions tested did not confirm the hypothetical transcription factor network of parotid differentiation, activation of the PSP promoter + intron clone by Mist1 was confirmed. The next step after determining this activation will be to confirm the Mist1/Tcf3 binding sites in the intron region by site-directed mutagenesis. This will validate that activation is from these transcription factors acting directly at the binding site, and it can determine if there is a preferential binding site. This future work will be done in the laboratory, but there could be clinical use of confirming transcriptional interactions.

Parotid gland ablation from head and neck radiation therapies, infection, inflammation, medications, and Sjögren's Syndrome (SS) can be debilitating [5, 15]. Patients suffering from any of these conditions lose proper parotid gland function and will develop xerostomia [17]. This can lead to a declining oral health 
resulting in periodontitis and cavities. Determining the genes involved in parotid differentiation could aid in the development of therapeutics involving molecular targets and in developing improved diagnostics. Although numerous transcription factor pathways still need to be validated, the successful confirmation of PSP promoter activation by Mist1 and Tcf3 is a stepping-stone to the development of gene therapies and enhancing diagnostic tools. My work, together with other reports, suggests that transgenic expression of Mist1 may help maintain parotid function in patients. 


\section{REFERENCES}

1. Proctor, G.B. and G.H. Carpenter, Regulation of salivary gland function by autonomic nerves. Auton Neurosci, 2007. 133(1): p. 3-18.

2. Pfaffe, T., et al., Diagnostic potential of saliva: current state and future applications. Clin Chem, 2011. 57(5): p. 675-87.

3. Kagami, H., S. Wang, and B. Hai, Restoring the function of salivary glands. Oral Dis, 2008. 14(1): p. 15-24.

4. Ann, D.K., H.H. Lin, and E. Kousvelari, Regulation of Salivary-GlandSpecific Gene Expression. Critical Reviews in Oral Biology \& Medicine, 1997. 8(3): p. 244-252.

5. S.-U. Gorr, S.G.V., D.S. Darling, Parotid Secretory Granules: Crossroads of Secretory Pathways and Protein Storage. Critical Reviews in Oral Biology \& Medicine, 2005. 84(6): p. 500 - 509.

6. Castle, D. and A. Castle, Intracellular Transport and Secretion of Salivary Proteins. Critical Reviews in Oral Biology \& Medicine, 1998. 9(1): p. 4-22.

7. Melvin, J.E., et al., Regulation of fluid and electrolyte secretion in salivary gland acinar cells. Annu Rev Physiol, 2005. 67: p. 445-69.

8. Gresz, V.K., T.H.; Hurley, P.T.; Varga, G.; Zelles, T.; Nielsen, S.; Case, R.M.; and Steward, M.C., Identification and localization of aquaporin water channels in human salivary glands. Am J Physiol Gastrointest Liver Physiol, 2001. 281(1): p. G247-G254.

9. Hoque, A.T., et al., Expression of the aquaporin 8 water channel in a rat salivary epithelial cell. J Cell Physiol, 2002. 191(3): p. 336-41.

10. Humphrey, S.P.a.W., R.T., A review of saliva: Normal composition, flow, and function. The journal of Prosthetic Dentistry, 2001. 85(2): p. 162-169.

11. Tabak, L.A., Structure and Function of Human Salivary Mucins. Critical Reviews in Oral Biology \& Medicine, 1990. 1(4): p. 229-234.

12. Iontcheva, I.O., F.G.; and Troxler, R.F., Human salivary mucin MG1 selectively forms heterotypic complexes with amylase, proline-rich proteins, statherin, and histatins. Journal of Dental Research, 1997. 76(3): p. 734-743.

13. Harunaga, J., J.C. Hsu, and K.M. Yamada, Dynamics of salivary gland morphogenesis. J Dent Res, 2011. 90(9): p. 1070-7.

14. Sivakumar, S., et al., Secretory protein expression patterns during rat parotid gland development. The Anatomical Record, 1998. 252(3): p. 485497.

15. Larsen, M., K.M. Yamada, and K. Musselmann, Systems analysis of salivary gland development and disease. Wiley Interdiscip Rev Syst Biol Med, 2010. 2(6): p. 670-82. 
16. Ryu, O.H., et al., Identification of parotid salivary biomarkers in Sjogren's syndrome by surface-enhanced laser desorption/ionization time-of-flight mass spectrometry and two-dimensional difference gel electrophoresis. Rheumatology (Oxford), 2006. 45(9): p. 1077-86.

17. Gaubitz, M., Epidemiology of connective tissue disorders. Rheumatology (Oxford), 2006. 45 Suppl 3: p. iii3-4.

18. Vitali, C.B., S; Jonsson, R; Moutsopoulos, H.M.; Alexander, E.L; Carsons, S.E.; Daniels, T.E.; Fox, P.C.; Fox, R.I.; Kassan, S.S.; Pillemer, S.R.; Talal, N.; Weisman, M.H.; and the European Study Group on Classification Criteria for Sjogren's Syndrome, Classification criteria for Sjogren's syndrome: a revised version of the European criteria proposed by the American-European Consensus Group. Ann Rheum Dis, 2002. 61(6): p. 554-558.

19. Liew, M.Z., M.; Kim, E.; Akpek, E.K., Prevalence and predictors of Sjogren's syndrome in a prospective cohort of patients with aqueousdeficient dry eye. Br J Ophthalmol, 2012. 96(12): p. 1498-1503.

20. Kalk, W.W.I.V., A.; Stegenga, B.; Bootsma, H.; Nieuw Amerongen, A.V.; Kallenberg, C.G.M Sialometry and sialochemistry: a non-invasive approach for diagnising Sjogren's Syndrome. Ann Rheum Dis, 2002. 61(2): p. 137-144.

21. Delporte, C.O.C., B.C; He, X.; Lancaster, H.E.; O'Connell, A.C.; Agre, P.; and Baum, B.J., Increased fluid secretion after adenoviral-mediated transfer of the aquaporin-1 cDNA to irradiated rat salivary glands. Proc. Natl. Acad. Sci. , 1997. 94(7): p. 3268-3273.

22. Baum, B.J., et al., Transfer of the AQP1 $c D N A$ for the correction of radiation-induced salivary hypofunction. Biochim Biophys Acta, 2006. 1758(8): p. 1071-7.

23. Baum, B.J., et al., Early responses to adenoviral-mediated transfer of the aquaporin-1 cDNA for radiation-induced salivary hypofunction. Proc Natl Acad Sci U S A, 2012. 109(47): p. 19403-7.

24. Ingenuity IPA Software - Pathway Analysis, miRNA, NGS, RNA-Seq, Microarrays, Gene Expression, Biomarkers.

25. Schibler, A.-C.P.a.U., Mouse Alpha-amylase Loci, Amy-1a and Amy-2a, are Closely Linked. Journal of Molecular Biology, 1985. 182: p. 359-365.

26. F. Sierra, A.-C.P., and U. Schibler, Different Tissue-Specific Expression of the Amylase Gene Amy-1 in Mice and Rats. Molecular and Cellular Biology, 1986. 6(11): p. 4067-4076.

27. Wiebauer, K.G., D.L.; Jones, J.M.; Caldwell, R.M.; Hartle, H.T.; and Meisler, M.H., A 70-kilobase reigon of mouse chromosome 3 contains salivary and pancreatic amylase genes and a pseudogene. Proc Natl Acad Sci U S A, 1985. 82(16): p. 5446-5449.

28. U. Schibler, P.H.S., F. Sierra, O. Hagenbuchle, P.K. Wellauer, M. Carneiro, and R. Walter, Structrual arrangement and tissue-specific expression of the two murine alpha-amylase loci Amy-1 and Amy-2. Oxford surverys on eukaryotic genes, 1986. 3: p. 210-34. 
29. Ting, C.N., et al., Endogenous retroviral sequences are required for tissue-specific expression of a human salivary amylase gene. Genes \& Development, 1992. 6(8): p. 1457-1465.

30. Poulsen, K.J., B.K.; Mikkelson, B.M.; Harmark, K.; Nielson, J.T.; and Hjorth, J.P., Coordination of murine parotid secretory protein and salivary amylase expression. The EMBO Journal, 1986. 5(8): p. 1891-1896.

31. Zheng, C.H., M.P.; McMillan, T.; Kleinman, H.K.; and O'Connell, B.C., Growth Factor Regulation of the Amylase Promoter in a Differentiating Salivary Acinar Cell Line. Journal of Cellular Physiology, 1998. 177(4): p. 628-635.

32. Nikitkova, A.E., E.M. Haase, and F.A. Scannapieco, Taking the starch out of oral biofilm formation: molecular basis and functional significance of salivary alpha-amylase binding to oral streptococci. Appl Environ Microbiol, 2013. 79(2): p. 416-23.

33. Sugino, H., Comparative genomic analysis of the mouse and rat amylase multigene family. FEBS Lett, 2007. 581(3): p. 355-60.

34. Scannapieco, F.A.T., G.; and Levine, M.J., Salivary a-Amylase: Role in Dental Plaque and Caries Formation. Critical Reviews in Oral Biology \& Medicine, 1993. 4(3): p. 301-307.

35. Fisher, S.Z., et al., Structure of human salivary alpha-amylase crystallized in a C-centered monoclinic space group. Acta Crystallogr Sect F Struct Biol Cryst Commun, 2006. 62(Pt 2): p. 88-93.

36. Ragunath, C., et al., Probing the role of aromatic residues at the secondary saccharide-binding sites of human salivary alpha-amylase in substrate hydrolysis and bacterial binding. J Mol Biol, 2008. 384(5): p. 1232-48.

37. Scannapieco, F.A.B., E.J.; Reddy, M.S.; and Levine, M.J., Characterization of salivary alpha-amylase binding to Streptococcus sanguis. Infect. Immun., 1989. 57(9): p. 2853-2863.

38. Vasseur, S., et al., Structural and functional characterization of the mouse p8 gene: promotion of transcription by the CAAT-enhancer binding protein alpha (C/EBPalpha) and C/EBPbeta trans-acting factors involves a C/EBP cis-acting element and other regions of the promoter. Biochem. J., 1999. 343(2): p. 377-383.

39. Mallo, G.V.F., F.; Calvo, E.L.; Ortiz, E.M.; Vasseur, S.; Keim, V.; Morisset, J.; and lovanna, J.L., Cloning and Expression of the Rat $p 8 \mathrm{cDNA}$, a New Gene Activated in Pancrease during the Acute Phase of Pancreatitis, Pancreatic Development, and Regeneration, and Which Promotes Cellular Growth. The Journal of Biological Chemistry, 1997. 272(51): p. 3236032369.

40. S. Vasseur, G.V.M., F. Fiedler, H. Bodeker, E. Canepa, S. Moreno, and J.L. Iovanna, Cloning and expression of the human p8, a nuclear protein with mitogenic activity. European Journal of Biochemistry, 1999. 259: p. 670-675. 
41. Ball, W.D.M., L.; and Hand, A.R., PSP and Smgb: a model for development and functional regulation in the rat major salivary glands. Biochemical Society Transactions, 2003. 31: p. 777-780.

42. Svendsen, P.K., K.; and Hjorth, J.P., Protein-binding elements in the proximal parotid secretory protein gene enhancer esential for salivarygland-specific expression. Biochem. J., 2001. 357: p. 537-544.

43. Bingle, C.D. and S.U. Gorr, Host defense in oral and airway epithelia: chromosome 20 contributes a new protein family. Int J Biochem Cell Biol, 2004. 36(11): p. 2144-52.

44. Abdolhosseini, M., et al., Human parotid secretory protein is a lipopolysaccharide-binding protein: identification of an anti-inflammatory peptide domain. Molecular and Cellular Biochemistry, 2012. 359(1-2): $p$. 1-8.

45. Bingle, L., et al., Characterisation and expression of SPLUNC2, the human orthologue of rodent parotid secretory protein. Histochem Cell Biol, 2009. 132(3): p. 339-49.

46. Bingle, C.D.a.C., C.J., PLUNC: A novel family of candidate host defence proteins expressed in the upper airways and nasopharynx. Hum. Mol. Genet. , 2002. 11(8): p. 937-943.

47. Gorr, S.U., et al., Dual host-defence functions of SPLUNC2/PSP and synthetic peptides derived from the protein. Biochem Soc Trans, 2011. 39(4): p. 1028-32.

48. Capoccia, B.J., et al., The ubiquitin ligase Mindbomb 1 coordinates gastrointestinal secretory cell maturation. J Clin Invest, 2013. 123(4): p. 1475-91.

49. Braganca, J., et al., Physical and functional interactions among AP-2 transcription factors, $p 300 / C R E B$-binding protein, and CITED2. J Biol Chem, 2003. 278(18): p. 16021-9.

50. Ishimoto, H. and R.B. Jaffe, Development and function of the human fetal adrenal cortex: a key component in the feto-placental unit. Endocr Rev, 2011. 32(3): p. 317-55.

51. Leung, M.-K.J., T.; Michels, C.L.; Livingston, D.M.; and Bhattacharya, S., Molecular Cloning and Chromosomal Localiztion of the Human CITED2 Gene Encoding p35srj/Mrg1. Genomics, 1999. 61: p. 307-313.

52. Haase, M., et al., CITED2 is expressed in human adrenocortical cells and regulated by basic fibroblast growth factor. J Endocrinol, 2007. 192(2): p. 459-65.

53. Bamforth, S.D., et al., Cardiac malformations, adrenal agenesis, neural crest defects and exencephaly in mice lacking Cited2, a new Tfap2 coactivator. Nat Genet, 2001. 29(4): p. 469-74.

54. Bhattacharya, S., et al., Functional role of p35srj, a novel p300/CBP binding protein, during transactivation by HIF-1. Genes \& Development, 1999. 13(1): p. 64-75.

55. Rikitake, Y. and E. Moran, DNA-binding properties of the E1A-associated 300-kilodalton protein. Molecular and Cellular Biology, 1992. 12(6): $p$. 2826-2836. 
56. Ojuka, E.O.G., V.; and Smith, J.A.H., The role of CaMKII in regulating GLUT4 expression in skeletal muscle. Am J Physiol Endocrinol Metab, 2012. 303: p. E322-E331.

57. De Luca, A.S., A.; De Paolis, P.; Cottone, G.; De Luca, L.; De Falco, M.; Porcellini, A.; Volpe, M.; and Condorelli, G. , p300/cAMP-responseelement-binding-protein ('CREB')-binding protein (CBP) modulates cooperation between myocyte enhancer factor $2 A(M E F 2 A)$ and thyroid hormone receptor-retinoid $X$ receptor. Biochem. J., 2003. 369: p. 477-484.

58. Oberste-Berghaus, C., Thyroid Hormone-independent Interaction between the Thyroid Hormone Receptor beta 2 Amino Terminus and Coactivators. Journal of Biological Chemistry, 2000. 275(3): p. 1787-1792.

59. Sartorelli, V.H., J.; Hamamori, Y.; and Kedes, L., Melcular mechanisms of myogenic coactivation by p300: direct interaction with the acitvatio domain of MyoD and with the MADS box of MEF2C. Mol. Cell. Biol., 1997. 17(2): p. 1010-1026.

60. Condorelli, G., Human p300 Protein Is a Coactivator for the Transcription Factor MyoD. Journal of Biological Chemistry, 1996. 271(15): p. 90099013.

61. Molkentin, J.D.B., B.L.; Martin, J.F.; and Olson, E.N., Cooperative Activation of Muscle Gene Expression by MEF2 and Myogenic bHLH Proteins. Cell, 1995. 83(7): p. 1126-1136.

62. Hamada, H.F., T.; Miyamoto, M.; Kimura, Y.; Maruyama, M.; Furia, A.; Miyata, T.; and Taniguchi, T., Structurally similar but funcitonally distinct factors, IRF-1 and IRF-2, bind to the same regulatory elements of IFN and IFN-inducible genes. Cell, 1989. 58(4): p. 729-739.

63. Tanaka, N.K., T.; and Taniguchi, T., Recognition DNA sequences of interferon regulatory factor 1 (IRF-1) and IRF-2, regulators of cell growth and the interferon system. Molecular and Cellular Biology, 1993. 13(8): $p$. 4531-4538.

64. Darnell, J.E.K., I.M.; and Stark, G.R., Jak-STAT Pathways and Transcriptional Activation in Response to IFNs and Other Extracellular Signaling Proteins. Science, 1994. 263(5164): p. 1415-1421.

65. Taniguchi, T.O., A.T; and Tanaka, N., IRF Family of Transcription Factors as Regulators of Host Defense. Annu. Rev. Immunol. , 2001. 19: p. 623655.

66. Weisz, A.M., P.; Sharf, R.; Appella, E.; Driggers, P.H.; Ozato, K.; Levi, B, Human interferon consensus sequence binding protein is a negative regulator of enhancer elements comme to interferon-inducible genes.

67. Watanabe, N.S., J.; Hovanessian, A.G.; Taniguchi, T.; and Fujita, T., Activation of IFN-beta element by IRF-1 requires a post-translational event in addition to IRF-1 synthesis. Nucleic Acids Research, 1991. 19(16): $p$. 4421-4428.

68. Fujii, Y.S., T.; Kusumoto, M.; Kyogoku, Y.; Taniguchi, T.; and Hakoshima, T., Crystal structure of an IRF-DNA complex reveals novel DNA recognition and cooperative binding to a tandem repeat of core sequences. The EMBO Journal, 1999. 18(18): p. 5028-5041. 
69. Birnbaum, M.J.v.Z., B.; Vaughan, P.S.; Whitmarsh, A.J.; van Wijen, A.J.; Davis, R.J.; Stein, G.S.; and Stein, J.L., Phosphorylation of the Oncogenic Transcription Factor Interferon Regulatory Farctor 2 (IRF2) In Vitro and In Vivo. Journal of Cellular Biochemistry, 1997. 66: p. 175-183.

70. Mizutani, T., et al., Homeostatic erythropoiesis by the transcription factor IRF2 through attenuation of type I interferon signaling. Exp Hematol, 2008. 36(3): p. 255-64.

71. Jesse, T.L.L., R.; lademarco, M.F.; and Dean, D.C, Interferon regulatory factor-2 is a transcriptional activator in muscle where it regulates expression of vascular cell adhesion molecule-1. The Journal of Cell Biology, 1998. 140(5): p. 1265-1276.

72. Vaughan, P.S., Cell Cycle Regulation of Histone H4 Gene Transcription Requires the Oncogenic Factor IRF-2. Journal of Biological Chemistry, 1998. 273(1): p. 194-199.

73. Ge, X., et al., PCAF acetylates \{beta\}-catenin and improves its stability. Mol Biol Cell, 2009. 20(1): p. 419-27.

74. Shen, D.W., et al., Cisplatin resistance: a cellular self-defense mechanism resulting from multiple epigenetic and genetic changes. Pharmacol Rev, 2012. 64(3): p. 706-21.

75. Vicent, G.P., et al., Minireview: role of kinases and chromatin remodeling in progesterone signaling to chromatin. Mol Endocrinol, 2010. 24(11): p. 2088-98.

76. Mateo, $\mathrm{F}$., et al., The transcriptional co-activator $P C A F$ regulates cdk2 activity. Nucleic Acids Res, 2009. 37(21): p. 7072-84.

77. Liu, L.S., D.M.; Trievel, R.C.; Zhang, H.B.; Marmorstein, R.; Halazonetis, T.D.; and Berger, S.L., p53 sites acetylated in vitro by PCAF and p300 are acetylated in vivo in response to DNA damage. Mol. Cell. Biol., 1999. 19(2): p. 1202-1209.

78. Zhao, L.Y., et al., PCAF is a coactivator for p73-mediated transactivation. Oncogene, 2003. 22(51): p. 8316-29.

79. Patel, J.H., et al., The $c-M Y C$ oncoprotein is a substrate of the acetyltransferases $h$ GCN5/PCAF and TIP60. Mol Cell Biol, 2004. 24(24): p. 10826-34.

80. Okumura, K., et al., PCAF modulates PTEN activity. J Biol Chem, 2006. 281(36): p. 26562-8.

81. Blanco, J.C.G., et al., The histone acetylase PCAF is a nuclear receptor coactivator. Genes \& Development, 1998. 12(11): p. 1638-1651.

82. Pickard, A., P.P. Wong, and D.J. McCance, Acetylation of Rb by PCAF is required for nuclear localization and keratinocyte differentiation. J Cell Sci, 2010. 123(Pt 21): p. 3718-26.

83. Masumi, A.W., I.-M.; Lefebvre, B.; Yang, X.-J.; Nakatani, Y.; and Ozato, $\mathrm{K}$., The histone acetylase PCAF is a phorbol-ester-inducuble coactivator of the IRF family that confers enhanced interferon responsiveness. Mol. Cell. Biol., 1999. 19(3): p. 1810-1820. 
84. Lemercier, C., et al., Mist1: A Novel Basic Helix-Loop-Helix Transcription Factor Exhibits a Developmentally Regulated Expression Pattern. Developmental Biology, 1997. 182(1): p. 101-113.

85. Massari, M.E. and C. Murre, Helix-Loop-Helix Proteins: Regulators of Transcription in Eucaryotic Organisms. Molecular and Cellular Biology, 2000. 20(2): p. 429-440.

86. Sobrado, V.R., et al., The class I bHLH factors E2-2A and E2-2B regulate EMT. J Cell Sci, 2009. 122(Pt 7): p. 1014-24.

87. Park, D., et al., The Drosophila Basic Helix-Loop-Helix Protein DIMMED Directly Activates PHM, a Gene Encoding a Neuropeptide-Amidating Enzyme. Molecular and Cellular Biology, 2008. 28(1): p. 410-421.

88. Patel, D. and J. Chaudhary, Increased expression of bHLH transcription factor E2A (TCF3) in prostate cancer promotes proliferation and confers resistance to doxorubicin induced apoptosis. Biochem Biophys Res Commun, 2012. 422(1): p. 146-51.

89. Pin, C.L., et al., The bHLH transcription factor Mist1 is required to maintain exocrine pancreas cell organization and acinar cell identity. J Cell Biol, 2001. 155(4): p. 519-30.

90. Guo, X., et al., Cloning, expression, and functional characterization of zebrafish Mist1. Biochem Biophys Res Commun, 2007. 359(1): p. 20-6.

91. Pin, C.L.B., A.C.; Konieczny, S.F., Mist1 expression is a common link among serous exocrine cells exhibiting regulated exocytosis. The Anatomical Record, 2000. 259(2): p. 157-167.

92. Johnson, C.L., et al., Mist1 is necessary for the establishment of granule organization in serous exocrine cells of the gastrointestinal tract. Mech Dev, 2004. 121(3): p. 261-72.

93. Luo, X., et al., Aberrant localization of intracellular organelles, Ca2+ signaling, and exocytosis in Mist1 null mice. J Biol Chem, 2005. 280(13): p. $12668-75$.

94. Tian , X., et al., RAB26 and RAB3D Are Direct Transcriptional Targets of MIST1 That Regulate Exocrine Granule Maturation. Molecular and Cellular Biology, 2010. 30(5): p. 1269-1284.

95. Sigvardsson, M., et al., Early B-Cell Factor, E2A, and Pax-5 Cooperate To Activate the Early $B$ Cell-Specific mb-1 Promoter. Molecular and Cellular Biology, 2002. 22(24): p. 8539-8551.

96. Ellenberger, T., et al., Crystal structure of transcription factor E47: E-box recognition by a basic region helix-loop-helix dimer. Genes \& Development, 1994. 8(8): p. 970-980.

97. Bain, G.E., I.; Robanus Maandag, E.C.; te Riele, H.P.; Voland, J.R.; Sharp, L.L.; Chun, J.; Huey, B.; Pinkel, D.; and Murre, C., E2A deficiency leads to abnormalities in alphabeta $T$-cell development and to rapid development of T-cell lymphomas. Mol. Cell. Biol., 1997. 17(8): p. 47824791.

98. Eckner, R., et al., Interaction and functional collaboration of $p 300 / C B P$ and $b H L H$ proteins in muscle and B-cell differentiation. Genes \& Development, 1996. 10(19): p. 2478-2490. 
99. Perez-Moreno, M.A., et al., A new role for E12/E47 in the repression of Ecadherin expression and epithelial-mesenchymal transitions. J Biol Chem, 2001. 276(29): p. 27424-31.

100. Perk, J., A. lavarone, and R. Benezra, Id family of helix-loop-helix proteins in cancer. Nat Rev Cancer, 2005. 5(8): p. 603-14.

101. Hawley-Nelson, P., V. Ciccarone, and M.L. Moore, Transfection of cultured eukaryotic cells using cationic lipid reagents. Curr Protoc Mol Biol, 2008. Chapter 9: p. Unit 94.

102. Gorr, S.U., S.G. Venkatesh, and D.S. Darling, Parotid Secretory Granules: Crossroads of Secretory Pathways and Protein Storage. Journal of Dental Research, 2005. 84(6): p. 500-509.

103. ATCC, 3T3-L1 cells lose contact inhibition and adipogenic potential when maintained in culture at confluence. AP Notes, 2013.

104. Augustowska, K.G., E.L., Exposure of human JEG-3 cell line to TCDD alters progesterone secretion but does not act on their viability and apoptosis. Organohalogen Compounds, 2004. 66.

105. Baker, O.J.C., J.M.; Redman, R.S.; Jones, J.E.; Seye, C.I.; Erb, L.; and Weisman, G.A., Proinflammatory cytokines tumor necrosis factor-a and interferon-g alter tight junction structure and function in the rat parotid gland Par-C10 cell line. Am J Physiol Cell Physiol, 2008. 295(5): p. C1191-C1201.

106. Kain, S.R.G., S., Overview of Genetic Reporter Systems. Curr Protoc Mol Biol, 2001. Chapter 9: p. Unit 9.6.

107. Lou, X., et al., Negative feedback regulation of NF-kappaB action by CITED2 in the nucleus. J Immunol, 2011. 186(1): p. 539-48.

108. Masumi, A., et al., Interferon regulatory factor-2 regulates cell growth through its acetylation. J Biol Chem, 2003. 278(28): p. 25401-7.

109. Lemercier, C., et al., The basic helix-loop-helix transcription factor Mist1 functions as a transcriptional repressor of MyoD. EMBO J, 1998. 17(5): p. 1412-1422. 


\section{CURRICULUM VITAE}

NAME: Sara Perez

ADDRESS: $\quad 2011$ Frankfort Ave. \#215

Louisville, KY 40206

DOB: $\quad$ Atlanta, GA - September 8, 1987

EDUCATION

\& TRAINING:

B.S., Biology

University of Georgia

$2006-2010$

\section{RESEARCH PROJECTS AND AWARDS:}

- Poster presentation, Research Louisville, UofL, 2012.

TITLE: "Characterization of Transcriptional Activator Binding Sites in the Parotid Secretory Protein Promoter" by S. Perez, A.L. Carenbauer, D.S. Darling.

- Summer Research Stipend Award, Dental School, UofL, 2012.

- Poster presentation, Research Louisville, UofL, 2011.

TITLE: "Regulation of Mouse Amylase 1 Gene Expression through

Transcriptional Repressors" by S. Perez, A.L. Carenbauer, D.S. Darling.

- Summer Research Stipend Award, Dental School, UofL, 2011. 